\title{
Chapter 14 \\ Behaviour of Metastable and Stable Austenitic Stainless Steels Under Planar-Biaxial Load
}

\author{
Carl H. Wolf, Sebastian Henkel and Horst Biermann
}

\begin{abstract}
The aim of the present study was to investigate the behaviour of a powder metallurgically produced high alloy X5CrMnNi16-7-6 metastable austenitic stainless steel under planar-biaxial loading. For this purpose, cruciform specimens made of this material were subjected both to quasi-static loading and to cyclic loading for low cycle fatigue and crack growth investigations. In addition to quasi-static shear loading with load axes force ratio $\lambda=-1$ and quasi-static equibiaxial loading with $\lambda=1$, further specimens were subjected to a load ratio of $\lambda=0.5$ to determine the yield surface. Quasi-static sequence tests with permanently changing $\lambda$ were carried out to determine load sequence effects. The characterization of the low cycle fatigue behavior was carried out under equibiaxial tensile loading with load axes strain ratio $\Phi=1$ and shear loading with $\Phi=-1$. Furthermore, investigations were carried out at different strain ratios. The description of the low cycle fatigue lives was performed using the Basquin-Manson-Coffin relationship. For both quasi-static and LCF experiments, the martensite content was measured in situ, so that the influence of the phase transformation on the material behaviour could be described. The fatigue crack growth investigations were performed on cruciform specimens under uniaxial, equibiaxial and initially equibiaxial and subsequently phase-shifted loading on a stable austenitic steel variant. In order to describe the fatigue crack growth, a finite element (FE) analysis of the specimen geometry was carried out first, so that a correlation between force and resulting stress in the uncracked specimen could be established. A geometry function for straight growing cracks was established by correlation between force and resulting stress in the specimen and $K$-solution
\end{abstract}

\author{
C. H. Wolf $(\varangle) \cdot$ S. Henkel $\cdot$ H. Biermann \\ Institute of Materials Engineering, Technische Universität Bergakademie Freiberg, \\ Gustav-Zeuner-Str. 5, 09599 Freiberg, Germany \\ e-mail: Carl.Wolf@ww.tu-freiberg.de \\ S. Henkel \\ e-mail: henkel@ww.tu-freiberg.de \\ H. Biermann \\ e-mail: biermann@ww.tu-freiberg.de


at different crack lengths. A comparison of the crack growth between uniaxial or equibiaxial and phase-shifted loading with kinking crack paths was made by means of Paris law.

\subsection{Introduction}

On real components, multiaxial stress states often occur. These are caused, for example, by stress gradients in the area around notches, but also by several simultaneously acting loads in different directions. Even in material testing, an exclusively uniaxial material test is rarely carried out, since necking in the tensile test of plastically deformable materials already represents a multiaxial loading condition [1].

In the present work, a newly developed, high-alloy, metastable austenitic stainless steel is studied under multiaxial quasi-static as well as multiaxial low-cyclic fatigue (LCF) loading. Moreover, multiaxial fatigue crack growth (FCG) was investigated. This steel exhibits the TRIP effect [2, 3] (TRansformation Induced Plasticity) caused by a transformation of $\gamma$-austenite to $\alpha^{\prime}$-martensite via a hexagonal structure called $\varepsilon$ martensite [4-8]. The phase transformations take place with volume effects, i.e. during the phase transformation from $\gamma$-austenite to $\varepsilon$-martensite a volume contraction and during the subsequent phase transformation from $\varepsilon$-martensite to $\alpha^{\prime}$-martensite a volume expansion occur.

Knowledge of the influence of the TRIP effect on the deformation and strain hardening behavior under multiaxial loading is relevant for the application of this material. With this expertise, forming processes can be simulated and safety reserves of e.g. pipes and pressure vessels can be calculated. Moreover, in the automotive industry, increasingly complex forming processes require knowledge of yield surface and strain hardening behavior $[9,10]$. Often only uniaxial material data is available for calculations and component design, so that multiaxial stress cases are usually converted into uniaxial equivalent stress cases [1]. Various transmission hypotheses are usually used for this purpose. For ductile materials, the distortion energy hypothesis according to von Mises, Huber and Hencky is usually utilized, which was initially established as a yield condition. For brittle materials, the maximum normal stress theory according to Rankine is applied. These hypotheses can be utilized to describe most technical applications for isotropic materials under static loading. The better the material behavior is phenomenologically known, the better are the results of e.g. the finite element method calculations. This also includes the knowledge of the yield surface and the elastic-plastic deformation behaviour [11]. For the purpose of generating defined multiaxial stress states under quasi-static loading, planar-biaxial experiments on cruciform specimens are suitable [9, 12, 13].

In addition to the interest in quasi-static multiaxial stress states, there has been an interest in the influence of various multiaxial strain states on crack initiation and crack propagation behavior for more than 40 years $[14,15]$. Unfortunately, there are only few data in the literature with different phase shifts $\varphi$ between the principal strains $\varepsilon_{1}$ and $\varepsilon_{2}$ in the range of $0^{\circ} \leq \varphi \leq 180^{\circ}$ [16-18]. Some authors determined the 
longest fatigue life under shear loading, i.e. with $\lambda=-1$, compared to other loading cases like uniaxial or biaxial tension [16, 19-22]. Pascoe and de Villiers [20] found, that the fatigue life for specimens loaded equibiaxially, i.e. with $\lambda=1$, had the shortest fatigue life. Ogata and Takahashi [16] stated, that fatigue life for uniaxially loaded specimens is even shorter than for equibiaxially loaded specimens. Many authors [16, 17, 19-23] correlated fatigue life $N_{f}$ with the von Mises equivalent strain amplitude $\Delta \varepsilon_{\mathrm{vM}} / 2$ as a scalar parameter. Furthermore, numerous theories have been established for the calculation of fatigue life under multiaxial loadings in the LCF regime, see e.g. [14, 16, 20, 24-29]. Uniaxial cyclic investigations on metastable high-alloy austenitic steels like AISI 301 and $304 \mathrm{~L}$ showed, that the formation of $\alpha^{\prime}$-martensite led to an increasing stress amplitude, i.e. the strength increased significantly during cyclic deformation. Consequently, this leads to higher fatigue life in high-cycle fatigue and to a reduction of the fatigue life in the LCF regime in comparison to a stable steel [7, 30-33].

The calculation of fatigue life for fatigue crack growth is also often based on uniaxial data [34-37]. However, components are often multiaxially loaded due to their geometry or loadings in different directions [38, 39], e.g. thin walled structural components as pressure vessels [40] or the outer skin of an aircraft [41, 42] as well as blade integrated disks in aircraft engines [43, 44]. During the service life of the components, both in-phase and out-of-phase loadings can occur. The change from inphase to out-of-phase loading can lead to crack branching [45-49] as well as kinking of the crack path $[49,50]$. To test the influence of such loading conditions on FCG, cruciform specimens serve as a link between uniaxial laboratory tests and complex component tests [40], since they can be used to investigate the material behaviour under well-defined biaxial stress conditions [9, 43].

Up to now, there is no standardized specimen design for cruciform specimens, but there are five commonly used specimen designs. These specimen designs differ in the specimen thickness, i.e. uniform specimen thickness or thinned out measuring area, the radius between the load arms and the design of the load arms. Thin specimens of uniform thickness and with (i) large radii between the load arms were examined e.g. by [51-53], (ii) small radii between the loading arms were examined e.g. by [47, 50, 54-61] and (iii) small radii between the loading arms as well as relief slits within the load introduction arms were examined e.g. by [41, 42, 53, 60, 62]. Specimens with (iv) a thickness-reduced measuring area and small radii between the loading arms were examined e.g. by [16, 43, 44, 53, 63-67]. The specimen design (v), used by many researchers $[40,45,46,48,49,56,59,60,63,68-80]$, was realized by inserting relief slits in the load introduction arms of specimen design (iv). These slits realize a good decoupling of the forces, as it was shown in [81].

A disadvantage of these many specimen geometries is that there is no simple formula or rather solution to calculate the stress intensity factor $K$ or rather its range $\Delta K$, i.e. for both straight and curved crack paths, thus, the $K$-solution must be determined material-dependently. This calculation can be time-consuming so that it is not always carried out. The consequence is that for planar-biaxial crack growth experiments, the crack growth is described in different dependencies: (i) exclusive consideration of the fatigue crack growth in $a-N$ plots, as done e.g. by [44, 50], (ii) consideration 
of the fatigue crack growth in $\mathrm{d} a / \mathrm{d} N-N$ plots, as done by Neerukatti et al. [49], (iii) consideration of the fatigue crack growth in $\mathrm{d} a / \mathrm{d} N-a$ plots, as done by Wang et al. [79], (iv) consideration of the fatigue crack growth in $\mathrm{d} a / \mathrm{d} N-\Delta G$ plots, see [47, 55], and (v) consideration of the fatigue crack growth in $a-N$ plots as well as crack growth rate plots (d $a / \mathrm{d} N-\Delta K$ plots), as done by many authors, cf. e.g. [40, 41, 45, $46,48,51,52,54-56,58,61,66-70,74-78,80]$. In this article, both $a-N$ plots and $\mathrm{d} a / \mathrm{d} N-\Delta K$ plots are used for the study of the fatigue crack growth. Furthermore, a comparison with the Paris law is made.

\subsection{Materials and Methods}

\subsubsection{Material}

A newly developed metastable austenitic stainless steel X5CrMnNi16-7-6 called $\gg 16-7-6 \ll$ in the following was studied. A significant characteristic of this material is the TRansformation Induced Plasticity, called TRIP effect [2, 3]. It is achieved by a transformation of $\gamma$-austenite to $\alpha^{\prime}$-martensite via a hexagonal structure called $\varepsilon$-martensite [4-8]. The main alloying elements are chromium $(\approx 16 \mathrm{wt} . \%)$, manganese $(\approx 7 \mathrm{wt} . \%)$ and nickel ( $\approx 6 \mathrm{wt} . \%)$. The chemical compositions of the individual batches for the various investigations varied slightly and are given in Table 14.1. However, these variations result in a pronounced martensitic transformation, as with $\gg 16-7-6$ (Batch 1)《 and »16-7-6 (Batch 2)«, or the material is rather stable, as in $\gg 16-7-6($ Batch 3$) \ll$. The »16-7-6 (Batch 1)« was used for the quasi-static investigations, the »16-7-6 (Batch 2)《 was used for the LCF investigations and the »16-7-6 (Batch 3) « was used for the fatigue crack growth investigations. All materials were produced by powder metallurgy (PM).

The powder for the specimens was manufactured by inert gas atomisation (TLS, Bitterfeld, Germany). It was subsequently hot pressed under vacuum at a temperature of $1050^{\circ} \mathrm{C}$ at a pressure of $30 \mathrm{MPa}$ to a circular blank (Fraunhofer IKTS, Dresden, Germany). The heating and cooling rate was $10 \mathrm{~K} / \mathrm{min}$. The blanks had a thickness of $(\mathrm{i}) \approx 11 \mathrm{~mm}$ and a diameter of $\approx 140 \mathrm{~mm}$ for the quasi-static specimens, (ii) a thickness of $\approx 16 \mathrm{~mm}$ and a diameter of $\approx 140 \mathrm{~mm}$ for the LCF specimens and

Table 14.1 Chemical compositions of the investigated steel in wt.\%. The composition of the elements marked with * was determined by spark emission. The composition of the elements marked with $^{* *}$ and with ${ }^{* * *}$ was determined by combustion method and by melt extraction, respectively

\begin{tabular}{l|l|l|l|l|l|l|l}
\hline & $\mathrm{Fe}^{*}$ & $\mathrm{Cr}^{*}$ & $\mathrm{Mn}^{*}$ & $\mathrm{Ni}^{*}$ & $\mathrm{C}^{* *}$ & $\mathrm{~N}^{* * *}$ & $\mathrm{Si}^{*}$ \\
\hline 16-7-6 (Batch 1) & Bal. & 15.9 & 6.2 & 6.2 & 0.05 & 0.04 & 0.9 \\
\hline 16-7-6 (Batch 2) & Bal. & 16.1 & 6.0 & 6.0 & 0.04 & 0.04 & 0.9 \\
\hline 16-7-6 (Batch 3) & Bal. & 16.2 & 7.2 & 6.7 & 0.049 & 0.056 & 0.94 \\
\hline
\end{tabular}


(iii) a thickness of $\approx 15 \mathrm{~mm}$ and a diameter of $\approx 150 \mathrm{~mm}$ for the fatigue crack growth specimens. However, the cross-shaped biaxial-planar specimens have dimensions of (i), (iii) $332 \mathrm{~mm} \times 332 \mathrm{~mm}$, or (ii) $197 \mathrm{~mm} \times 197 \mathrm{~mm}$, respectively, so that the discs were welded into a commercial AISI304 base material. For this purpose, the following production steps were carried out:

1. A hole with a diameter of (i) and (iii) $140 \mathrm{~mm}$, or (ii) $130 \mathrm{~mm}$ was cut by water jet cutting into the square plates made of AISI304 (PRO VA Blechbearbeitung $\mathrm{GmbH}$, Olbernhau, Germany) with a thickness of (i) and (ii) $10 \mathrm{~mm}$ or (iii) $15 \mathrm{~mm}$ and an edge length of (i) and (iii) $340 \mathrm{~mm}$, or (ii) $200 \mathrm{~mm}$.

2. The hole in the square plate was enlarged to a diameter of (i) and (iii) $144.8 \mathrm{~mm}$, or (ii) $134.8 \mathrm{~mm}$ by milling.

3. The circular blanks were milled to a diameter of (i) and (iii) $145 \mathrm{~mm}$, or (ii) $135 \mathrm{~mm}$ and a height of (i) and (ii) $10 \mathrm{~mm}$, or (iii) $15 \mathrm{~mm}$.

4. Afterwards the circular blanks were cooled with liquid nitrogen for $30 \mathrm{~min}$ and subsequently placed into the squared plates, so that a specimen base plate is formed from one circular blank and one squared plate, which are held together by means of an interference fit.

5. The circular blank and the squared plate of the specimen base plate were welded together using an electron beam.

6. Afterwards, the specimen base plates were solution annealed at $1050{ }^{\circ} \mathrm{C}$ for $30 \mathrm{~min}$ and then quenched with nitrogen at 9 bar $(\mathrm{G}+\mathrm{M}$ Vacutherm Härterei-und Oberflächentechnik GmbH, Brand-Erbisdorf, Germany).

7. Then, the specimens base plates were milled into their cruciform specimen shape, cf. Fig. 14.1.

8. The specimens for quasi-static investigations and for fatigue crack growth investigations were further mechanically processed after milling:

- Quasi-static specimens:

The slits of the »Triple-slit« and the »Double-slit« specimens were subsequently inserted by water jet cutting, cf. Fig. 14.1a, b.

- Fatigue crack growth specimens:

A hole with diameter of $d=4 \mathrm{~mm}$ was drilled in the middle of the specimens. Afterwards, two notches with a length of $l=3 \mathrm{~mm}$ each were inserted by electro-discharge machining, cf. Fig 14.1d.

9. Finally, the surfaces were polished mechanically.

\subsubsection{Quasi-static Loading}

The cruciform specimens for quasi-static tests were designed according to [82-84]. This geometry was developed using FE simulations with the aim of a homogeneous stress and strain distribution in the measuring area. In this work, two different specimen geometries were used, which are based on those proposed by [83, 84]. The 
(a)

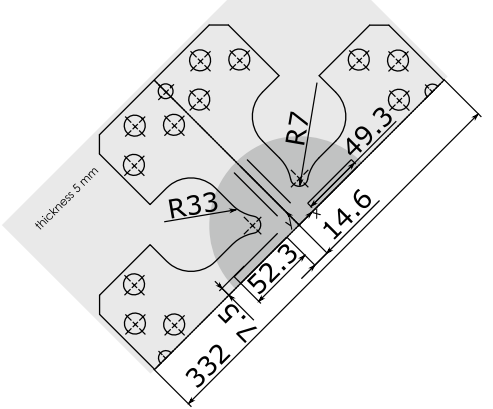

(c)

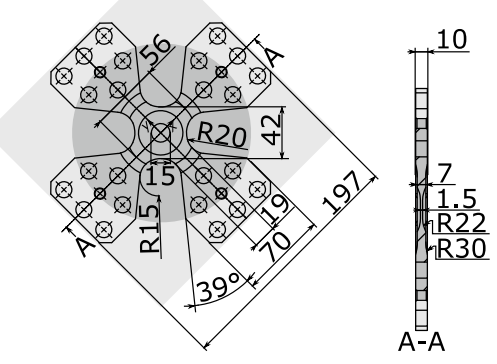

(b)

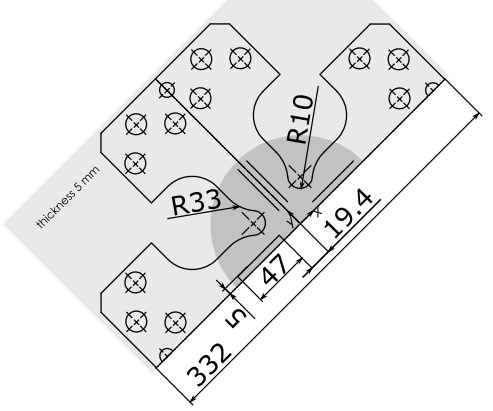

(d)

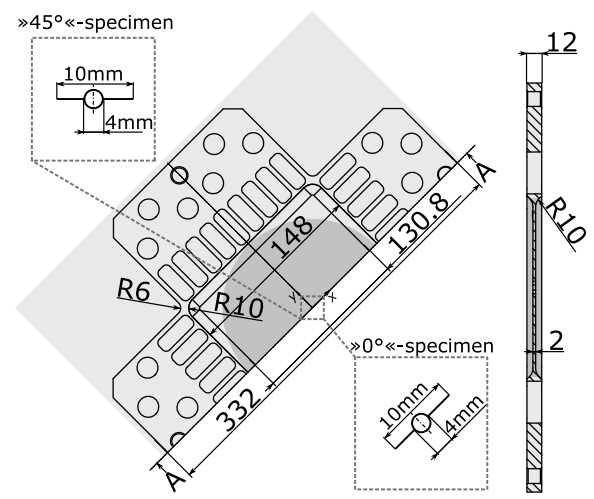

Fig. 14.1 Cruciform specimen geometries for biaxial-planar $\mathbf{a}, \mathbf{b}$ quasi-static, $\mathbf{c}$ low cycle fatigue as well as $\mathbf{d}$ fatigue crack growth investigations with the essential dimensions in $\mathrm{mm}$ and the material illustration: light grey represents AISI304 and dark grey represents PM. Quasi-static specimen with a 3 slits (»Triple-slit« specimen) and b 2 slits (»Double-slit« specimen). d Fatigue crack growth specimen with notches aligned parallel to one loading axis ( $\gg 0^{\circ} \ll$-specimen, rectangle bottom right) and at an angle of $45^{\circ}$ to both load axes ( $\gg 45^{\circ} \ll$-specimen, rectangle top left)

thickness of the specimens was $5 \mathrm{~mm}$. The two specimen shapes used differ on the one hand in the number of slits within the loading arms and on the other hand in the transmission radius. The specimens with three slits called $\gg$ Triple-slit « specimen had a transmission radius of $7 \mathrm{~mm}$, cf. Fig. 14.1a. The specimens with two slits called »Double-slit« specimen had a transmission radius of $10 \mathrm{~mm}$, cf. Fig. 14.1b. The length of the slits was different for both specimens. On the »Triple-slit« specimen, the middle slit was longer than the slits to the left and right. The two slits of the »Double-slit« specimen had the same length and were shorter than the slits of the »Triple-slit« specimen. Furthermore, the »Triple-slit« specimen had a homogeneous stress and strain distribution in the area of the yield strength at equibiaxial loading with $\lambda=1$, where $\lambda$ is the load ratio of the forces of both loading axes according to 
(14.1). The »Double-slit« specimen also showed a homogeneous stress and strain distribution without stress and strain concentration areas. In particular, higher strains up to failure were possible in this case. Details of the two specimen designs are given in [85].

$$
\lambda=\frac{F_{x}}{F_{y}}
$$

with $F_{x}$ and $F_{y}$ the forces in axes $x$ and $y$, respectively.

In addition to tests with a constant load ratio, i.e. shear loading with $\lambda=-1$, equibiaxial loading with $\lambda=1$, and tests with $\lambda=0.5$, sequence tests with alternating $\lambda$ were also carried out to determine a part of the subsequent yield surface and characterize the hardening behavior as proposed by [86, 87]. The stresses were calculated using the partial unloading method [87]. Hooke's law was then used to calculate the principal stresses for the plane stress state [87].

The load ratios of the sequence tests were given in [85]. In addition to the biaxial tests, uniaxial tests were performed on both flat and cylindrical specimens. The flat specimens were tested on a MTS Landmark 250 (MTS Systems Corporation, Eden Prairie, USA).

\subsubsection{Low Cycle Fatigue}

The LCF experiments were performed on specimens with a planar thinned measuring area with a diameter of $15 \mathrm{~mm}$ and a thickness of $1.5 \mathrm{~mm}$. In the highly loaded measuring area in the middle of the specimens there was a homogeneous stress distribution. The specimen geometry is shown in Fig. 14.1c. The design was similar to that reported repeatedly in the literature, cf. e.g. [16-20, 23, 88].

The LCF tests were performed under total strain-control, whereby the strains $\varepsilon_{x}$ and $\varepsilon_{y}$ were measured by a biaxial extensometer (Sandner Messtechnik GmbH, Biebesheim, Germany). Different strain states $\Phi$, where $\Phi$ is the strain ratio of the strains of both axes, cf. (14.2), were investigated with a strain rate of $\dot{\varepsilon}=0.004 / \mathrm{s}$.

$$
\Phi=\frac{\varepsilon_{x}}{\varepsilon_{y}}
$$

In addition to equibiaxial tensile strain tests with $\Phi=1$ and shear tests with $\Phi=-1$, strain ratios of $\Phi=0.5, \Phi=-0.1$ and $\Phi=-0.5$ have also been tested. The schematic course of the triangular strain-time function for $\Phi=1$ is shown in Fig. 14.2a, for $\Phi=-1$ in Fig. 14.2b and for $\Phi=-0.5$ in Fig. 14.2c. For shear and for equibiaxial strain, the frequencies and amplitudes of the strains had the same values, Fig. 14.2a, b, while the amplitudes differed for $\Phi=-0.5$, cf. Fig. 14.2c.

The von Mises equivalent strain amplitude $\Delta \varepsilon_{\mathrm{vM}} / 2$ was calculated according to [89]. The tested von Mises equivalent strain amplitudes $\Delta \varepsilon_{\mathrm{vM}} / 2$ were in the range 

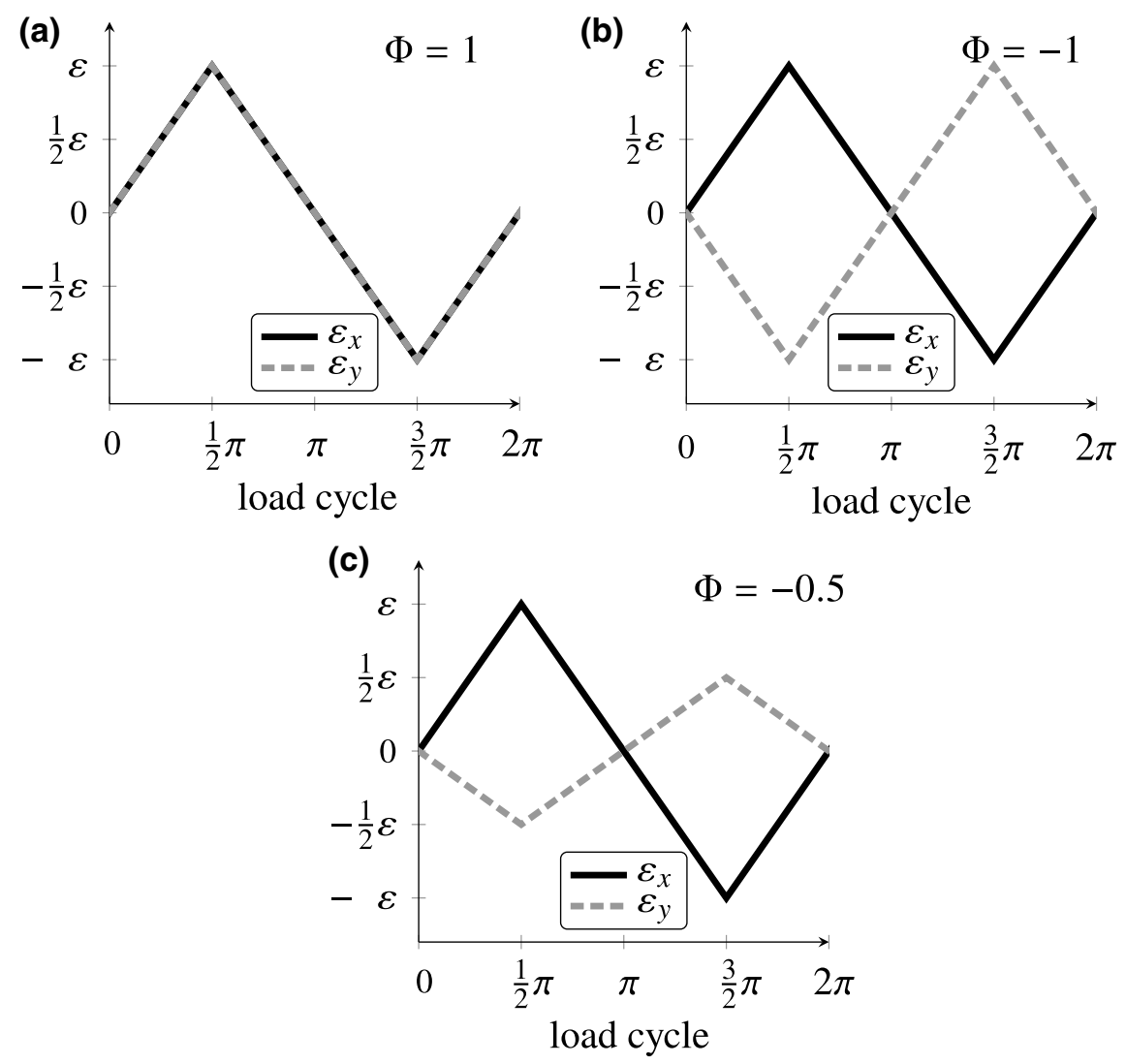

Fig. 14.2 Schematic course of the strains $\varepsilon_{x}$ and $\varepsilon_{y}$ for different strain ratios $\Phi$ for in-phase loading

of $0.3 \cdot 10^{-2} \leq \Delta \varepsilon_{\mathrm{vM}} / 2 \leq 0.6 \cdot 10^{-2}$. In addition, uniaxial reference tests were performed on a MTS Landmark 250 (Eden Prairie, USA).

The characterization of the cyclic deformation behaviour is based on the von Mises force amplitude $\Delta F_{\mathrm{vM}} / 2$ due to the fact that the cross section could not be determined and numerical calculations as performed by Itoh et al. [19] were not available. The calculation of $\Delta F_{\mathrm{vM}} / 2$ was carried out according to [18] using the forces $F_{x}$ and $F_{y}$ at maximum principal strains in axis $x$, cf. (14.3). It is assumed that hardening and yielding took place in a defined cross-section and the maximum stresses and strains occur in the thinned measuring area of the specimen with a homogeneous distribution.

$$
F_{\mathrm{vM}}=\sqrt{\left(F_{x}\right)^{2}+\left(F_{y}\right)^{2}-F_{x} \cdot F_{y}}
$$




\subsubsection{Fatigue Crack Growth}

The fatigue crack growth experiments were performed on cruciform specimens with a thinned measuring area and slitted arms as proposed by Brown and Miller [69] on the base of [81]. The design is widely used [40, 45, 46, 48, 49, 56, 59, 60, $63,68-80]$. It shall simulate the internal crack in a plate of infinite size and small thickness according to [90]. The slitted arms shall ensure a good decoupling of the forces [40, 81, 91]. Furthermore, the stresses in the cross section of the gauge area shall be higher compared to the stresses in the loading arms. The thickness of the measuring area was approximately $2 \mathrm{~mm}$. The exact specimen thickness may vary slightly due to polishing, so that the exact specimen thickness was measured after the tests.

Depending on the investigation, two different configurations of the start notch have been used [40, 76, 77, 91]. On the one hand, uniaxial investigations have been performed at the cruciform specimens with the notches aligned parallel to one loading axis, i.e. at an angle of $0^{\circ}$ to one loading axis. This kind of specimen is called $\gg 0^{\circ} \ll-$ specimen and shown in Fig. 14.1d. On the other hand, the equibiaxial as well as biaxial investigations with a phase shift have been performed on specimens with notches aligned at an angle of $45^{\circ}$ to both loading axes. This kind of specimen is called $\gg 45^{\circ} \ll-$ specimen and is also shown in Fig. 14.1d. The hole in the middle of both specimens had a diameter of $d=4 \mathrm{~mm}$. The total length of both notches was $2 \cdot a=10 \mathrm{~mm}$, i.e. the notches represented two cracks with a length of $a=5 \mathrm{~mm}$ each at the beginning of the investigation.

The length of the two cracks was calculated from the center of the cruciform specimen. As long as the crack grew straight, i.e. in the direction of the start notches, the crack length $a$ was measured as the Euclidean distance between starting notch tip and the respective crack tip. Subsequently, the radius of the hole, i.e. $d / 2=2 \mathrm{~mm}$, and the length of the notch, $l=3 \mathrm{~mm}$, were added to that Euclidean distance. As soon as the crack path kinked, the Euclidean distance between the currently observed measuring point and the previously observed measuring point was calculated. This distance was added to the crack length of the previously considered measuring point. This means that the crack length is ultimately the sum of the crack length of the straight crack and the individual crack lengths of the kinked crack path. Unfortunately, the measurement errors were added. To minimize measurement errors, the scatter band reduction proposed in [92] in accordance with ASTM E647 [93] was performed. In other words, the given crack length is the arc length of the crack.

The investigations were conducted force controlled with a frequency of $20 \mathrm{~Hz}$ and a force ratio of $R=0.1$. If a force ratio different to $R=0.1$ was used, it is indicated. The exact forces are given in a recent work [77]. In the case of uniaxial loading, the forces were applied just in $y$-direction. In the case of biaxial loading, the forces were applied in $x$ - and $y$-direction. The course of the forces for equibiaxial loading is shown in Fig. 14.3a. Figure 14.3b shows the course for phase-shifted loading with a phase shift of $\varphi=90^{\circ}$. The phase shift $\varphi$ is the time dependent shift of the two forces relative to each other. In the case of in-phase loading, the load ratio $\lambda$, cf. (14.1), 

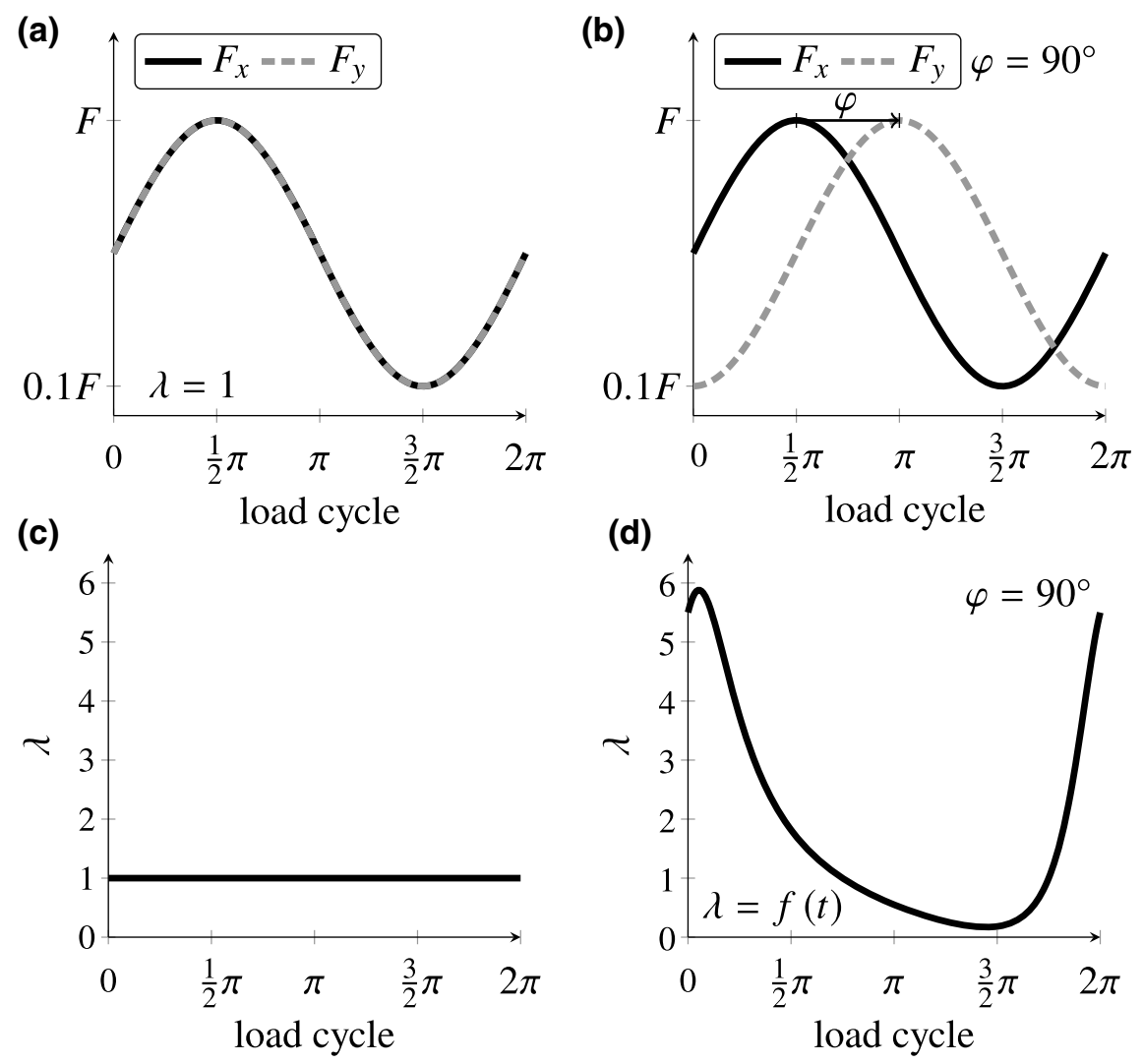

Fig. 14.3 Schematic course of $\mathbf{a}, \mathbf{b}$ the applied forces in $x$ - and $y$-direction and $\mathbf{c}, \mathbf{d}$ the resultant biaxial force ratio $\lambda$ during one load cycle for $\mathbf{a}, \mathbf{c}$ in-phase loading as well as $\mathbf{b}, \mathbf{d}$ ouf-of-phase loading with a phase shift of $\varphi=90^{\circ}$

was $\lambda=1$ during the entire load cycle, cf. Fig. 14.3c. In the case of out-of-phase loading, the load ratio $\lambda$ changed permanently during the load cycle, cf. Fig. 14.3d for the example of $\varphi=90^{\circ}$.

Four different load cases were investigated: (i) uniaxial loading, (ii) equibiaxial loading, (iii) first equibiaxial loading to start the fatigue crack growth and afterward phase-shifted loading, and (iv) first equibiaxial loading to start the fatigue crack growth and afterward phase-shifted loading with an increase of the phase shift after a change in the crack length $a$ of more than $\Delta a=1.5 \mathrm{~mm}$.

For the calculation of the stress intensity factor $K$ and range $\Delta K$, the occurring stresses have to be known. They were calculated using commercial software ABAQUS for 2D finite element analyses with a linear elastic material model and unit forces of $f_{x}=1 \mathrm{kN}$ or $f_{y}=1 \mathrm{kN}$ [91]. The investigations showed, that a materialindependent solution for the transmission of force into stress can be given. An applied force of $F_{y}=1 \mathrm{kN}$ in $y$-direction resulted in a stress of $\sigma_{y}=2.94 \mathrm{MPa}$ in $y$-direction 

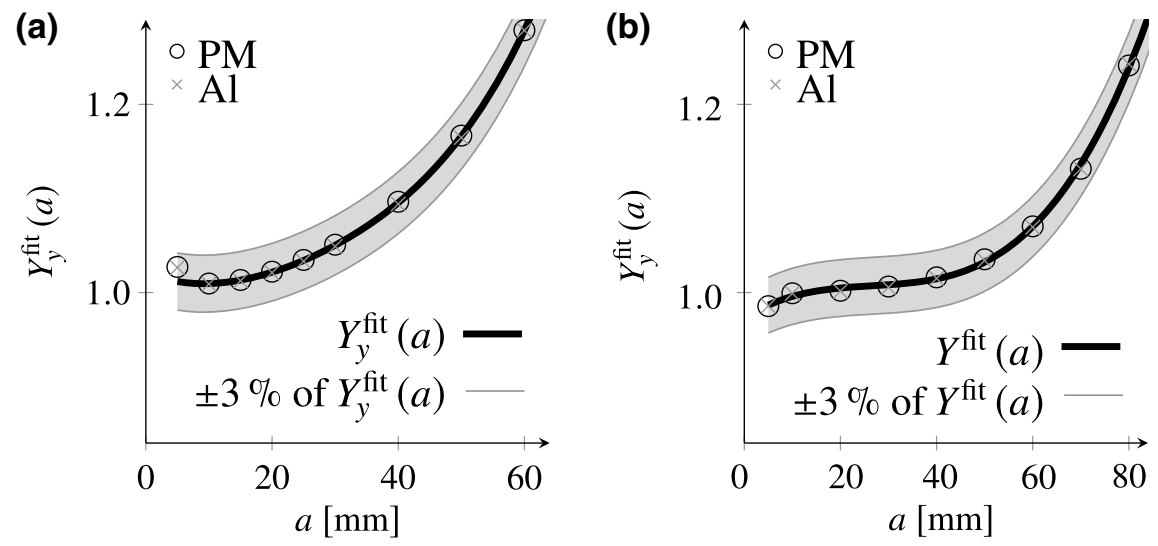

Fig. 14.4 Plot of the geometry functions $Y(a)$ versus the crack length $a$ for the $\mathbf{a} \gg 0^{\circ} \ll$-specimen and $\mathbf{b} \gg 45^{\circ} \ll$-specimen. Comparison of the exact solutions for PM and $\mathrm{Al}$ with the determined fit function and the $\pm 3 \%$ deviation [91]

in the center of the specimen. An applied force of $F_{x}=1 \mathrm{kN}$ in $x$-direction resulted in a stress of $\sigma_{y}=-0.05 \mathrm{MPa}$ in $y$-direction in the center of the specimen. Due to the principal of superposition and the possibility of scaling, cf. [40,76, 77, 91], the effective stress can thus be determined at each time of the load cycle. Furthermore, in dependence of the alignment of the start notches, i.e. for the $\gg 0^{\circ} \ll-$ specimen as well as for the $\gg 45^{\circ} \ll$-specimen, material-independent and crack length dependent geometry functions $Y(a)$ were determined, cf. [91]. Figure 14.4a, b show the geometry functions $Y_{y}(a)$ for the $\gg 0^{\circ} \ll$-specimen and $Y(a)$ for the $\gg 45^{\circ} \ll$-specimen, respectively. Both plots in Fig. 14.4 show the exact solution of the geometry factor $Y(a)$ at different crack lengths for the investigated steel, called PM, as well as for an aluminium alloy, called Al. The calculations are based on the material parameters Young's modulus $E=192 \mathrm{GPa}$ and Poisson's ratio $v=0.24$ for PM and $E=72 \mathrm{GPa}$ and $v=0.34$ for the $\mathrm{Al}$ alloy, respectively. It becomes clear, that the geometry functions approximate the calculated geometry factors well for both materials, in each case for the corresponding notch configuration for straight crack paths. Influences on the fatigue crack growth due to differences in the thickness of the measuring area can be corrected using a thickness correction [76]. As soon as the crack paths begin to kink, the calculation of the $K$-solution has to be done using FE-calculations, cf. [76, 77].

\subsubsection{Experimental Details}

The planar-biaxial investigations were performed on a servo-hydraulic tensioncompression system (Instron 8800, Instron, Norwood, USA), cf. Fig. 14.5. The test rig had four actuators in two perpendicular loading axes. In addition, depending on 
Fig. 14.5 Servo-hydraulic planar-biaxial tension-compression test system [1]

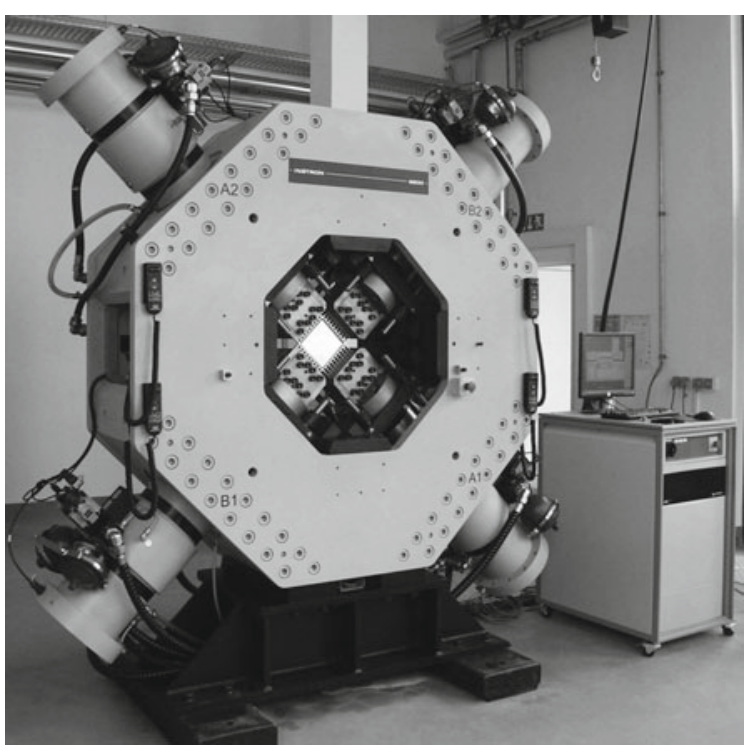

the test, i.e. quasi-static, LCF or FCG tests, various other measuring instruments were attached, cf. Fig. 14.6.

A biaxial orthogonal extensometer (Sandner Messtechnik GmbH, Biebesheim, Germany) was applied for the quasi-static investigations as well as for the LCF investigations, cf. \#1 in Fig. 14.6a, c, d. The extensometer had four ceramic arms with a gauge length of $13 \mathrm{~mm}$ for strain measurement in the two orthogonal axes. It was mounted in the middle of the measuring area at one side of the specimen, cf. \#1 in Fig. 14.6a for quasi-static investigations [85, 87] and \#1 in Fig. 14.6c, d for LCF investigations $[18,94]$. The measured strains corresponded to principal strains.

The ferrite measuring device Fischerscope MMS PC (Helmut Fischer GmbH, Sindelfingen, Germany), cf. \#2 in Fig. 14.6a, c, d, was applied at the quasi-static investigations as well as for the LCF investigations to measure the martensite content opposite to the extensometer. The martensite content was calculated according to [95] by multiplying the measured ferrite content calibrated for $\delta$-ferrite by a factor of 1.7 .

Support plates were mounted on the specimen during quasi-static tests with compressive loading, cf. \#3 in Fig. 14.6b to prevent buckling.

Fatigue crack growth tests were carried out by applying crack gages (Krak Gage B20, Russenberger Prüfmaschinen AG, Neuhausen, Switzerland) to the front of specimen, cf. \#4 in Fig. 14.6e. The crack length for cracks that extend the two start notches was measured using the indirect potential method using Fractomat (Russenberger Prüfmaschinen AG, Neuhausen, Switzerland).

Furthermore, a high speed camera (mvBlueCOUGAR-XD 104 bG, Matrix Vision GmbH, Oppenweiler, Germany), cf. \#5 in Fig. 14.6f, with optics was located at the back of the specimen to document the crack opening. For this purpose a speckle pattern was sprayed onto the specimen surface to evaluate the movement of the 
(a)

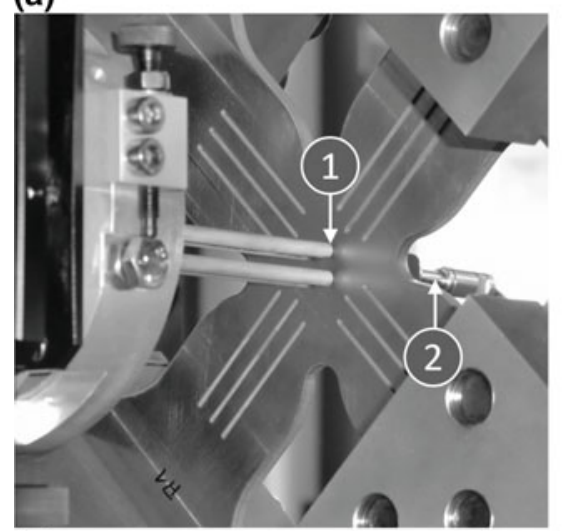

(c)
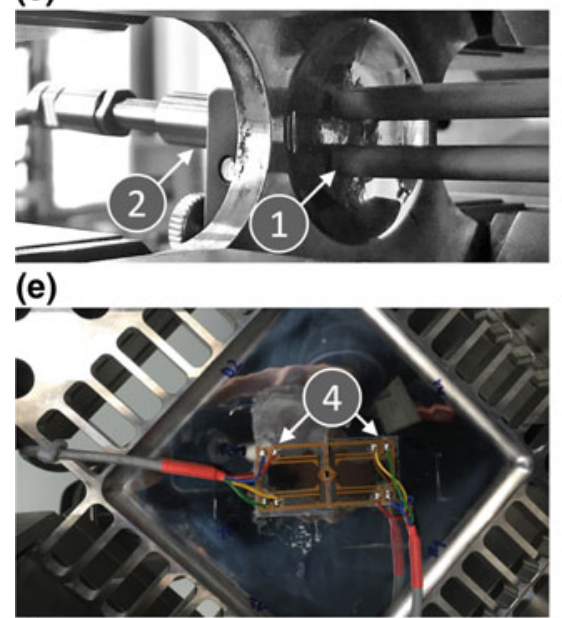

(f)

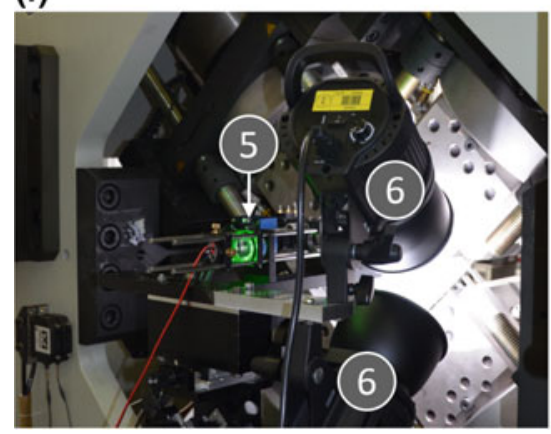

(b)

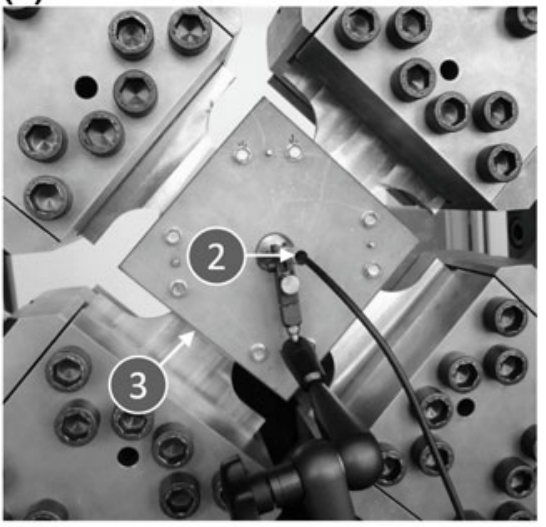

(d)

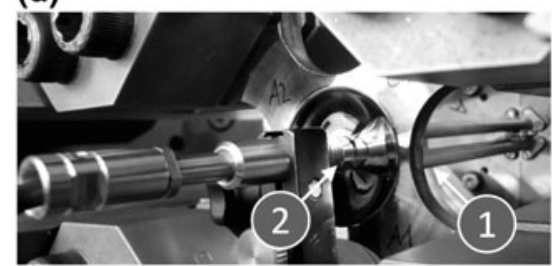

(g)

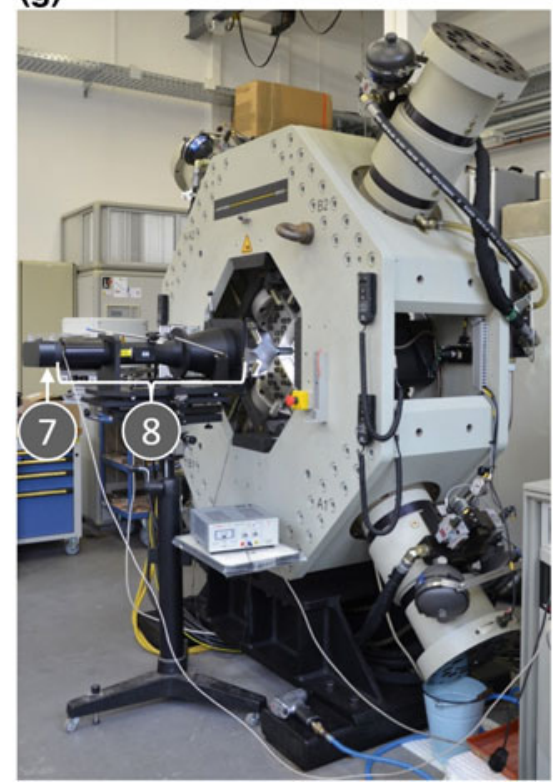

Fig. 14.6 Test setup for experiments with $\mathbf{a}$, b quasi-static loading as well as c, d low cycle fatigue and $\mathbf{e}-\mathbf{g}$ fatigue crack growth experiments and illustration of the measuring instruments used: \#1 biaxial orthogonal extensometer, \#2 ferrite sensor, \#3 support plates, \#4 crack gage, \#5 high speed camera, \#6 lighting, \#7 high resolution scanner camera with \#8 telecentric optics [23, 87] 
crack edges using digital image correlation software (ARAMIS v6.3.1, GOM GmbH, Braunschweig, Germany). For this, it was important that the measuring spot is uniformly illuminated. This was achieved with two LED spotlights (Mettle EL-600, Mettle Photographic Equipment Corporation, Changzhou, China), cf. \#6 in Fig. 14.6f.

The documentation of the crack tip coordinates and the measurement of the crack lengths for kinking crack paths was carried out with a line scanner camera (Pentacon SCAN 6000, Pentacon GmbH, Dresden, Germany) with telecentric optics, which was installed in front of the test rig, cf. \#7 and \#8 in Fig. 14.6g, cf. [71] for further details.

\subsection{Quasi-static Loading}

The evaluation of the uniaxial and the biaxial tests with constant load ratio $\lambda$ are shown in Fig. 14.7a. The yield point used was the $0.2 \%$ yield point $R_{\mathrm{p} 0.2}$ applied for materials without a pronounced yield point. The yield strength of the uniaxial tests was $288 \pm 21 \mathrm{MPa}$ in tension and $288 \pm 28 \mathrm{MPa}$ in compression. Furthermore the symmetry points for the uniaxial loading are indicated. This material can be described with the von Mises equivalent stress hypothesis. A comparison of the results between the $\gg$ Triple-slit« specimens and the $\gg$ Double-slit « specimens shows a higher equivalent yield strength of the $\gg$ Double-slit « specimens in comparison to the »Triple-slit« specimens. These differences are visible in quadrant I of the von Mises yield surface, cf. Fig. 14.7a. In quadrants II and IV, differences in yield strength between the two specimen geometries of up to $90 \mathrm{MPa}$ are visible.

The comparison of the stress-strain curve of the uniaxial experiments with the stress-strain curve of the »Double-slit « specimens illustrates, that the »16-7-6 (Batch $1) \ll$ can be described with the von Mises equivalent stress hypothesis. For shear loading, i.e. $\lambda=-1$, strains of up to $20 \%$ are possible. In the uniaxial experiments a significant scatter was found. The results of the biaxial tests are within this scatter band. From this it can be concluded that the partial unloading method is suitable for determining the stress-strain curve for those biaxial experiments.

By means of sequence tests on a $\gg$ Triple-slit « specimen and a $\gg$ Double-slit $\ll$ specimen the subsequent yield surfaces were studied. Load sequence effects occurred. In this paper, only the results of the $\gg$ Triple-slit« specimen are presented. The results of the »Double-slit« specimen are given elsewhere [85].

Figure 14.7b shows the load path and Fig. 14.7c shows the stress path in the principal stress plane $\sigma_{1}-\sigma_{2}$ of the $\gg$ Triple-slit« specimen. The corresponding stressstrain curve as well as the martensite evolution is given in Fig. 14.7d.

In the load sequence test of the $\gg$ Triple-slit « specimen, the load was first increased at a load ratio of $\lambda=0.3$ until (1) an equivalent plastic strain $\varepsilon_{\text {eq-pl }}$ of $\varepsilon_{\text {eq-pl }}=2 \%$ was reached, cf. Fig. 14.7c. At this equivalent plastic strain, the equivalent stress $\sigma_{\text {eq }}$ was $\sigma_{\text {eq }}=350 \mathrm{MPa}$. Therefore, the yield surface for $\sigma_{\text {eq }}=350 \mathrm{MPa}$ is shown in Fig. 14.7c (solid line) under the assumption of isotropic hardening. At this load, $0.3 \%$ of $\alpha^{\prime}$-martensite had already formed. Subsequently, the loading was gradually 

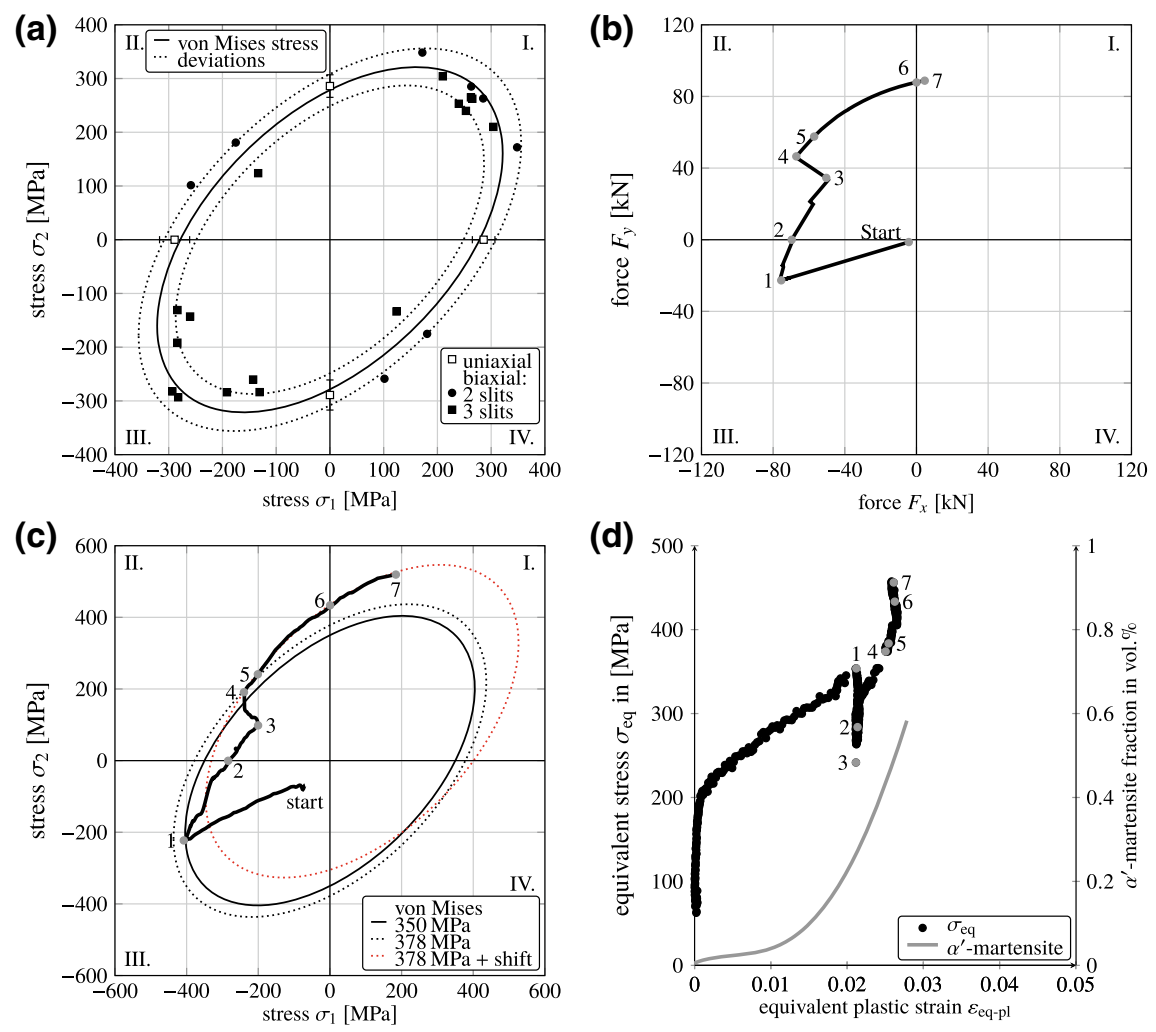

Fig. 14.7 Results of the quasi-static biaxial-planar experiments. a Experimentally determined von Mises yield surface of the »16-7-6 (Batch 1) « by uniaxial and planar-biaxial tests using the »Tripleslit« and the »Double-slit« specimens. b Load path and $\mathbf{c}$ stress paths of sequential tests within the principal stress plane with an initial load ratio of $\lambda=0.3$ at the $\gg$ Triple-slit $\ll$ specimen with $\mathbf{d}$ the corresponding stress-strain curve and martensite evolution [85]

changed, starting (1) with the initial load ratio of $\lambda=0.3$, through (2) a load ratio of $\lambda=0$ and ending (3) with a load ratio of $\lambda=-0.7$. The load path passed through the elastic area. When the load ratio of $\lambda=-0.7$ was reached, the force was again increased up to (4) an equivalent plastic deformation of $\varepsilon_{\text {eq-pl }}=2.5 \%$. Further $\alpha^{\prime}$ martensite was formed. At the equivalent plastic strain of $\varepsilon_{\text {eq-pl }}=2.5 \%$, an equivalent stress of $\sigma_{\mathrm{eq}}=378 \mathrm{MPa}$ was reached. In the subsequent gradual loading change, starting (4) with the load ratio of $\lambda=-0.7$ and ending (5) with a load ratio of $\lambda=$ -1 , the equivalent stress followed the yield surface for $\sigma_{\text {eq }}=378 \mathrm{MPa}$. The further stepwise change of the load ratio from (5) $\lambda=-1$ through (6) a load ratio of $\lambda=\infty$ to (7) $\lambda=20$ was accompanied by further hardening and a further $\alpha^{\prime}$-martensite formation without further plastic deformation, i.e. elastic material behaviour was observed. This effect can be explained by kinematic hardening, so that a shifted yield surface for $\sigma_{\text {eq }}=378 \mathrm{MPa}$ was drawn, cf. Fig. 14.7c, red dotted ellipse. The shift was 
$\sigma_{1}=90 \mathrm{MPa}$ and $\sigma_{2}=110 \mathrm{MPa}$. This ellipse corresponds to the observed loading path. This confirms the hypothesis of kinematic hardening which is accompanied by the formation of further $\alpha^{\prime}$-martensite. The stresses were determined by means of partial unloading method. The results showed that the partial unloading method is also suitable for the measurement of kinematic hardening effects under multiaxial loading.

In the presented sequence test as well as in the sequence test of [85], no yield surface matching the load path could be determined. The reason for this is the formation of $\alpha^{\prime}$-martensite. This results in the assumption that the $\alpha^{\prime}$-martensite formation of the microstructure depends on the stress state. Changes in the stress state led to an activation of other glide systems. An intersection of these with the martensite led to strain hardening. Detailed explanation on this are made in the following paragraphs on microstructure. It is also assumed that anisotropic yield surface is present since strain hardening is correlated with a combination of isotropic and kinematic hardening. As long as no $\alpha^{\prime}$-martensite formation took place, isotropic material behaviour was present. A similar material behaviour with initial isotropic flow curve and kinematic hardening during subsequent deformation can also be found in the literature [87, 96-98].

The investigations of the microstructure were performed ex situ at $\gg$ Tripleslit « specimen for shear loading with $\lambda=-1$ and equibiaxial tension with $\lambda=1$ up to equivalent strains of $\varepsilon_{\text {eq-pl }}=8.6 \%$ and $\varepsilon_{\text {eq-pl }}=8 \%$, respectively. The scanning electron microscope (SEM) images in back scattered electron (BSE) contrast clearly showed the formation of deformation bands in the austenitic matrix [85]. $\alpha^{\prime}$-martensite nuclei were formed in these deformation bands in accordance with uniaxial reference tests, see e.g. [99, 100]. Uniaxial monotonic tests by the authors of [100] showed that the deformation bands were areas of strain localizations. These form large stacking faults due to the movement of partial dislocations. The stacking fault density, the local strain and the thickness of the deformation bands increased with increasing plastic strain. The $\alpha^{\prime}$-martensite nuclei were preferentially formed on the intersection points of deformation bands or at intersection points of individual stacking faults with deformation bands. This in turn corresponds to the increase in strain as a function of the crystallographic orientation of the $\alpha^{\prime}$-martensite nuclei in relation to the load axis. Shear loading resulted in austenitic grains being covered with deformation bands containing $\alpha^{\prime}$-martensite islands. In contrast, tensile loading resulted in a lower density of the deformation bands. The individual deformation bands of the austenitic matrix can be distinguished. Furthermore, the $\alpha^{\prime}$-martensite island density was significantly lower for uniaxial loading.

The electron backscatter diffraction (EBSD) investigations of the microstructure of the $\gg$ Triple-slit« specimen for shear loading with $\lambda=-1$ and equibiaxial tension with $\lambda=1$ show significant differences, cf. Fig. 14.8. The number of austenite grains containing deformation bands is significantly higher for shear loading, cf. Fig. 14.8a, than for equibiaxial loading, cf. Fig. 14.8b. Furthermore, much more $\alpha^{\prime}$-martensite nuclei were formed under shear loading, i.e. the density of $\alpha^{\prime}$-martensite nuclei is much higher for shear loading in comparison to the equibiaxial tension loading. In the EBSD images it becomes clear that the formation of deformation bands was inten- 
(a)

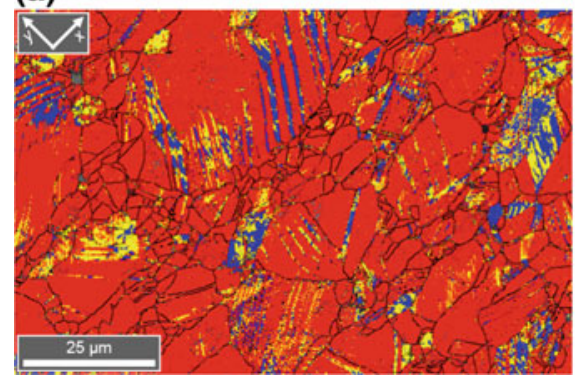

(b)

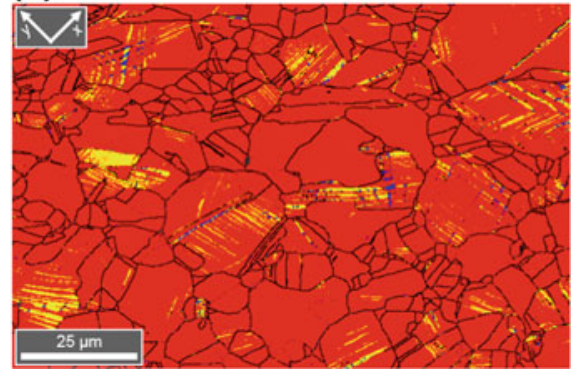

Fig. 14.8 EBSD phase maps of $\gg$ Triple-slit « specimens after a shear loading up to $\varepsilon_{\text {eq-pl }}=8.6 \%$ and $\mathbf{b}$ equibiaxial tensile loading up to $\varepsilon_{\text {eq-pl }}=8 \%$ with austenite (red), $\varepsilon$-martensite (yellow) and $\alpha^{\prime}$-martensite (blue) [85]

sified due to the high stacking fault density, which had a hexagonal structure, when subjected to shear loading. This is particularly evident from the fact that in the specimen subjected to shear loading, individual austenite grains were completely covered with a hexagonal structure, cf. Fig. 14.8a, and their thickness or rather their density were much more pronounced than for equibiaxial loading. Furthermore, the volume fraction of the deformation-induced $\alpha^{\prime}$-martensite is considerably higher for shear loading than for equibiaxial tensile loading. This corresponds to the measurements of the ferromagnetic phase fraction by means of a ferrite sensor [85].

\subsection{Low Cycle Fatigue}

The cyclic deformation behaviour and the martensitic transformation were investigated for $\gg 16-7-6$ (Batch 2)《. The characterization is based on the von Mises force amplitude $\Delta F_{\mathrm{vM}} / 2$. The LCF behaviour of the material can be divided into three stages, cf. Fig. 14.9 [94]. Due to the cyclic loading, primary hardening took place at the beginning. Subsequently softening took place, which was finally followed by secondary hardening. Such material behaviour is already well-known from uniaxial studies, see e.g. [7, 31, 32]. The course of the cyclic deformation curves for the investigated equibiaxial tensile loading, i.e. the strain ratios of $\Phi=1$ and $\Phi=0.5$, was almost identical, cf. [94]. However, with negative strain ratios $\Phi$, the von Mises force amplitude $\Delta F_{\mathrm{vM}} / 2$ decreased with decreasing strain ratio $\Phi$, cf. Fig. 14.9a.

With negative strain ratios, the onset of secondary hardening was earlier and the magnitude was increased, i.e. the more negative the strain ratio was, the stronger and earlier the secondary hardening was, cf. Fig. 14.9a. Furthermore, at negative strain ratios, it was found that the maximum fatigue life was measured for the strain ratio of $\Phi=-1$ and the shortest fatigue life for the strain ratio of $\Phi=-0.1$, i.e. the larger the strain ratio at negative strain ratio was, the longer the fatigue life was. This leads to the assumption that shear loading with $\Phi=-1$ supports yielding, secondary 

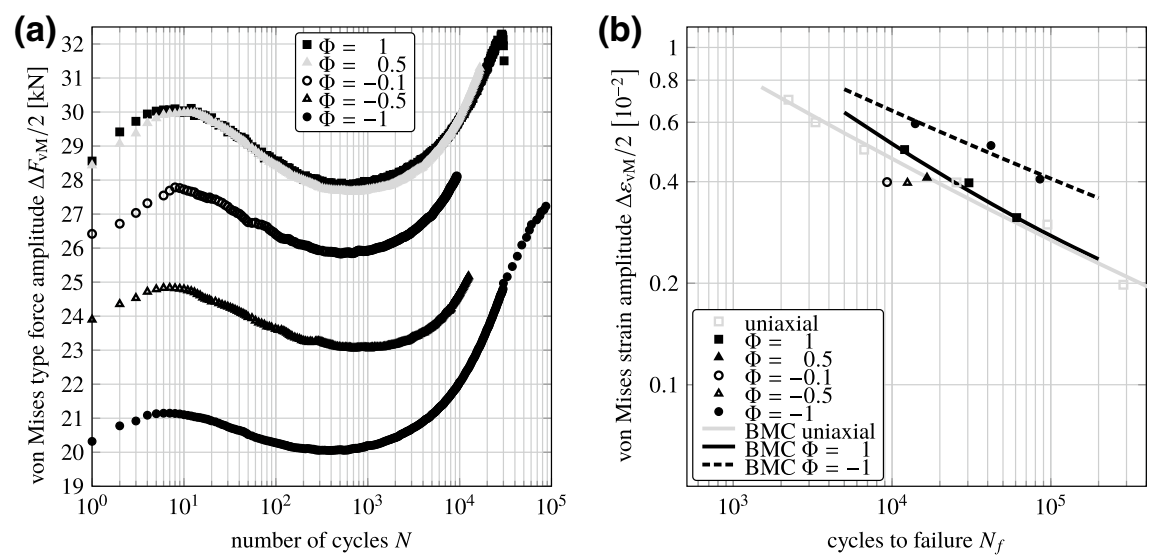

Fig. 14.9 a Cyclic deformation curves and b estimation of fatigue life of »16-7-6 (Batch 2)《 [94] under uniaxial and biaxial cyclic loading with different strain ratios $\Phi$ showing the von Mises equivalent strain amplitude of $\Delta \varepsilon_{\mathrm{vM}} / 2$ versus $N_{f}$ [94]

hardening and reduces axial forces. This was also reported in [18]. Due to the shear loading the secondary hardening was most pronounced due to an early start of cyclic hardening. Therefore the fatigue life for shear stress was also the highest.

In contrast to negative strain ratios, von Mises force amplitudes $\Delta F_{\mathrm{vM}} / 2$ were almost identical for positive strain ratios, cf. Fig. 14.9a. However, in these experiments the cross-sectional area was not identical, as was assumed for the von Mises force amplitude $\Delta F_{\mathrm{vM}} / 2$. Further experiments with an increase in von Mises strain amplitude $\Delta \varepsilon_{\mathrm{vM}} / 2$ in the range between $0.3 \cdot 10^{-2} \leq \varepsilon_{\mathrm{vM}} / 2 \leq 0.6 \cdot 10^{-2}$ showed an earlier onset of the secondary hardening due to a higher plastic deformation, as the martensitic phase transformation took place during the cyclic deformation.

For the investigated von Mises strain amplitude of $\Delta \varepsilon_{\mathrm{VM}} / 2=0.4 \cdot 10^{-2}$ for the strain ratios of $\Phi=-1, \Phi=-0.5, \Phi=-0.1, \Phi=0.5$ and $\Phi=1$ as well as for uniaxial experiments, a significant increase in the $\alpha^{\prime}$-martensite content was observed after an incubation period and correlated with the onset of secondary hardening, see [18]. The course of the martensite formation curves for the strain ratios of $\Phi=$ $-1, \Phi=-0.5, \Phi=-0.1$ and the uniaxial investigations were almost identical up to the point of failure. However, for the strain ratios of $\Phi=0.5$ and $\Phi=1$, the martensitic transformation started later. The $\alpha^{\prime}$-martensite amount at fatigue failure ranged from an $\alpha^{\prime}$-martensite amount of $5 \mathrm{vol} \%$ at a strain ratio of $\Phi=0.5$ up to an $\alpha^{\prime}$-martensite amount of $45 \mathrm{vol} \%$ at a strain ratio of $\Phi=-1$. In conclusion, it can be stated that the $\alpha^{\prime}$-martensite formation depends on the platic strain amplitude $\varepsilon_{\mathrm{vM}} / 2$, which is responsible for secondary hardening. This is in accordance to [7, 31, 32]. Furthermore, the formation of $\alpha^{\prime}$-martensite is promoted by uniaxial or shear loading, since the martensite content was significantly lower for all other types of loading, i.e. $\Phi=-0.5, \Phi=-0.1, \Phi=0.5$ and $\Phi=1$. 
(a)

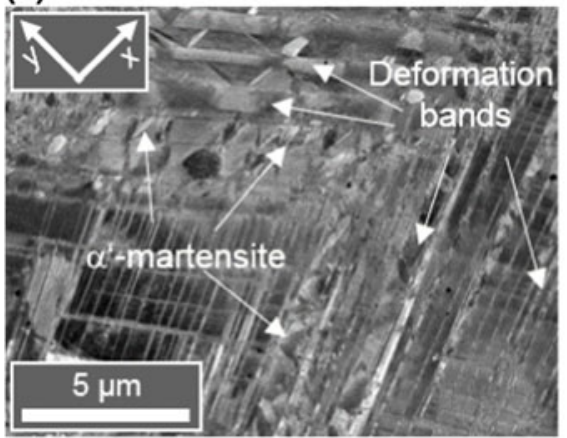

(c)

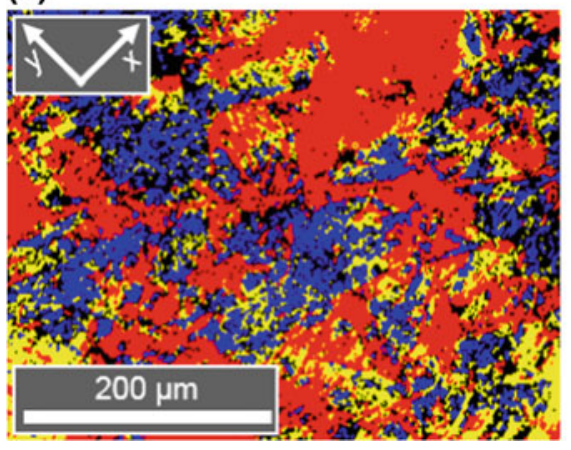

(b)

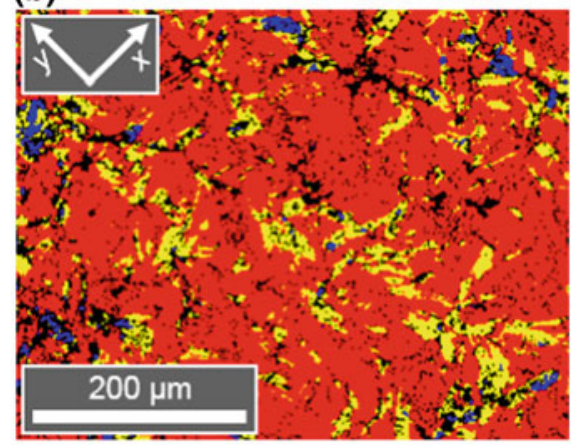

(d)

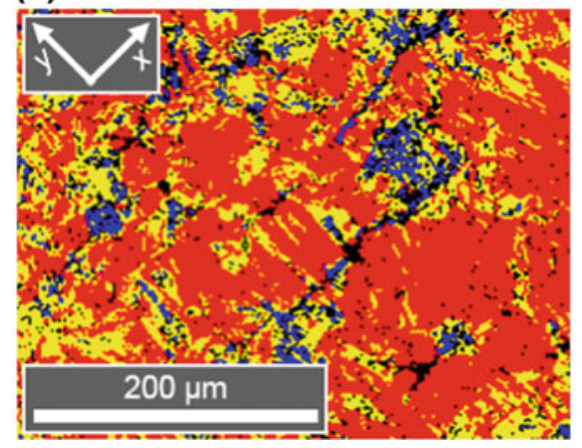

Fig. 14.10 SEM micrographs of the $\gg 16-7-6$ (Batch 2$) \ll$ after cyclic loading at $\Delta \varepsilon_{\mathrm{vM}} / 2=0.4$. $10^{-2}$. a Deformation bands and $\alpha^{\prime}$-martensite shown in the BSE contrast after cylclic shear loading with $\Phi=-1$. b-d EBSD phase maps after cyclic b equibiaxial loading with $\Phi=1$, $\mathbf{c}$ shear loading with $\Phi=-1$ and $\mathbf{d}$ loading with $\Phi=0.5$ with austenite (red), $\varepsilon$-martensite (yellow) and $\alpha^{\prime}$-martensite (blue) [94]

The SEM images in BSE contrast, cf. Fig. 14.10a, show lens-shaped $\alpha^{\prime}$-martensite in the deformation bands. These are often located at the intersection points of deformation bands [101]. This is a typical microstructure for cyclic deformation and in accordance with the observations of e.g. [5]. The thin deformation bands do not contain $\alpha^{\prime}$-martensite nuclei. This is also consistent with findings by the authors of [5]. A high stacking fault density resulting in a hexagonal structure called $\varepsilon$-martensite was found by EBSD and electron channeling contrast imaging (ECCI) in the deformation bands, cf. [5].

EBSD measurements were made in the SEM on vibration-polished surfaces, Fig. 14.10b-d. The phase maps show fcc austenite (red), hexagonal $\varepsilon$-martensite (yellow) and bcc $\alpha^{\prime}$-martensite (blue) at different von Mises strain ratios $\Phi$ at a von Mises strain amplitude of $\Delta \varepsilon_{\mathrm{vM}} / 2=0.4 \cdot 10^{-2}$. Figure $14.10 \mathrm{~b}-\mathrm{d}$ show the phase maps after cyclic deformation with equibiaxial loading of $\Phi=1$, shear loading of $\Phi=-1$, and deformation with $\Phi=-0.5$. It becomes clear that the $\alpha^{\prime}$ martensite always lies within the hexagonal phase (yellow). This in turn confirms the 
assumption that the transformation from fcc austenite to $\alpha^{\prime}$-martensite took place via $\varepsilon$-martensite. The comparison of Fig. 14.10b-d shows that the largest fraction of $\alpha^{\prime}$-martensite and $\varepsilon$-martensite were formed under shear loading with a fraction of $\approx 15 \%$ each, cf. Fig. 14.10c. The lowest fraction of $\alpha^{\prime}$-martensite and $\varepsilon$-martensite was measured under equibiaxial loading, cf. Fig. 14.10b. The most intensive formation of $\varepsilon$-martensite was found after a loading with a strain ratio of $\Phi=0.5$, although the regions with $\alpha^{\prime}$-martensite were very small, cf. Fig. 14.10d. A martensitic phase transformation was also measured in the plastic zone of the formed cracks. However, this is not shown here.

The fatigue life was compared by applying the von Mises strain amplitude $\Delta \varepsilon_{\mathrm{vM}} / 2$ versus the number of load cycles to failure, cf. Fig. 14.9b. The comparison of the fatigue life of the »16-7-6 (Batch 2)《 at different strain ratios shows clearly, that fatigue lives were the shortest for $\Phi=0.5, \Phi=-0.1$ and $\Phi=-0.5$ in comparison to the uniaxial as well as biaxial shear loading and the equibiaxial loading. To be more precise, these fatigue lives for uniaxial or equibiaxial loading are within the scatter band of 2. It can therefore be concluded that the Basquin-Manson-Coffin relationship (BMC) for uniaxial loading is conservative for equibiaxial loading for the investigated material. In contrast, the authors of [19] observed at AISI304 steel that the fatigue lives for $\Phi=-0.5, \Phi=0$ and $\Phi=0.5$ are between those of equibiaxial loading with $\Phi=1$ and shear loading with $\Phi=-1$. Fatigue life of the $\gg 16-7-6$ (Batch 2 ) $\ll$ under shear loading $\Phi=-1$ is about 7-8 times higher than under equibiaxial $\Phi=1$ or uniaxial loading, respectively. The differences in fatigue life decrease with increasing von Mises equivalent strain amplitude $\varepsilon_{\mathrm{vM}} / 2$ due to plastic deformation. This is in accordance with the findings of [18] for the cast material. Furthermore, the results show that the highest fatigue lives occurred at shear loading compared to uniaxial loading in agreement with the literature for planar biaxial investigations [16, $17,19,20,23]$ and tension-torsion tests [21, 22, 102]. For austenitic steels with a low stacking fault energy, the differences in fatigue lives are larger than for austenitic steels with a high stacking fault energy [22].

The discussion of the resulting equivalent force amplitudes and fatigue lives is based on the assumption of von Mises. However, the deviations of equivalent force amplitudes and fatigue lives can also be interpreted that the von Mises hypothesis cannot be applied in the present case. The von Mises criterion was used, as the criterion is valid for plastically deformable materials. Under equibiaxial loading in the tension-compression regime there is a scatter of about $2-3$, with a shorter fatigue life compared to uniaxial loading. Under shear loading the fatigue life is about 7-8.5 times higher than under uniaxial loading for the same von Mises strain amplitude, i.e. the damage caused by shear loading is overestimated. In order to be able to describe the service life reserve or the reduced damage caused by shear loading, alternative models should be used which take the effect of the hydrostatic part of the stress tensor on damage into account. 


\subsection{Fatigue Crack Growth}

\subsubsection{Crack Paths}

The fatigue crack growth investigations on the $\gg 16-7-6$ (Batch 3$) \ll$ were carried out on five different specimens. One specimen was loaded unaixially (specimen »uni $\ll$ ), one specimen was loaded equibiaxially (specimen »equi $\ll$ ), two specimens were first equibiaxially and subsequently phase-shifted loaded (specimens $\gg 0^{\circ} / 22.5^{\circ} \ll$ and $\left.\gg 0^{\circ} / 180^{\circ} \ll\right)$ and one specimen was first equibiaxially and then phase-shifted loaded with phase shift increases of $15^{\circ}$ after given crack growth intervals (specimen $\gg$ stepw. $\left.0^{\circ}-90^{\circ} \ll\right)$. The courses of the two cracks of the respective specimens were identical or symmetrical, respectively. This is also valid for the crack paths of all four cracks of specimen $\gg 0^{\circ} / 180^{\circ} \ll$. As expected, the uniaxial loading of specimen »uni « led to a straight crack path, which runs perpendicular to the loading axis $y$, cf. Fig. 14.11a. Furthermore, the equibaixial loading during the entire test of specimen $\gg$ equi $\ll$ resulted in a crack path that runs at an angle of $45^{\circ}$ to both loading axes in the direction of the starting notches, cf. Fig. 14.11b. This was due to the fact that the start notches were also aligned at an angle of $45^{\circ}$ to both loading axes and that the equibiaxial loading led to a pure Mode I crack opening. SEM investigation of the crack path revealed that there was a micro crack branching at the end of the investigation, cf. Fig. 14.12a. The reason for this seems to be an edge influence as well as force coupling.

A change of the phase shift from in-phase loading to out-of-phase loading led to a change of the crack propagation direction in most investigations. The change from the initial equibiaxial loading to a subsequent phase-shifted loading of $\varphi=22.5^{\circ}$ for specimen $\gg 0^{\circ} / 22.5^{\circ} \ll$ resulted in a gradual change of the crack propagation direction without branching, cf. Fig. 14.11c. Branching as a result of a phase-shifted loading occured after phase change to $180^{\circ}$ in specimen $\gg 0^{\circ} / 180^{\circ} \ll$, cf. Fig. $14.11 \mathrm{~d}$. At the triple point of cracks $1,1-1$ and 1-2, i.e. at the point where the change from in-phase to out-of-phase loading and therefore branching occured, no further micro cracks were observed in SEM investigations, cf. Fig. 14.12b. The obtained crack paths are in accordance with those predicted in [103]. However, it was expected that both branched cracks would grow initially, but one crack would not grow further after some load cycles [75]. Due to the change to a $\varphi=180^{\circ}$ phase-shifted loading, there were two principal stress directions which occured in succession. They were shifted by exactly half of the load cycle, i.e. $N / 2$. The cracks $1-1$ and $1-2$ or $2-1$ and 2-2, respectively, grew on initially curved paths, but then finally perpendicular to the principal stress directions. This is in accordance with [104, p. 131]. The cracks strived for this crack path according to the maximum circumferential stress criterion according to [105]. This criterion is commonly used for crack growth direction predictions [106-108].

The change from an initial in-phase loading to a subsequent $15^{\circ}$ phase-shifted loading of specimen $\gg$ stepw. $0^{\circ}-90^{\circ} \ll$ resulted in a kinking at a very small angle, Figs. 14.11e, f and 14.13a. This relatively small angle of crack path kinking was 
(a)

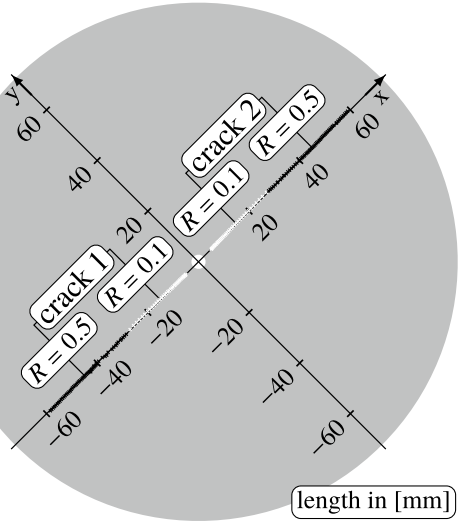

(c)

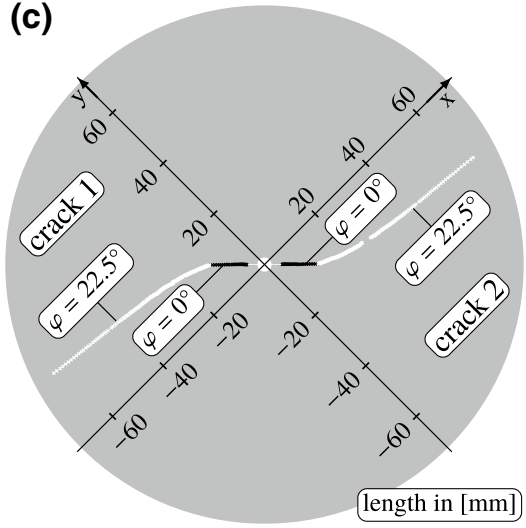

(e)

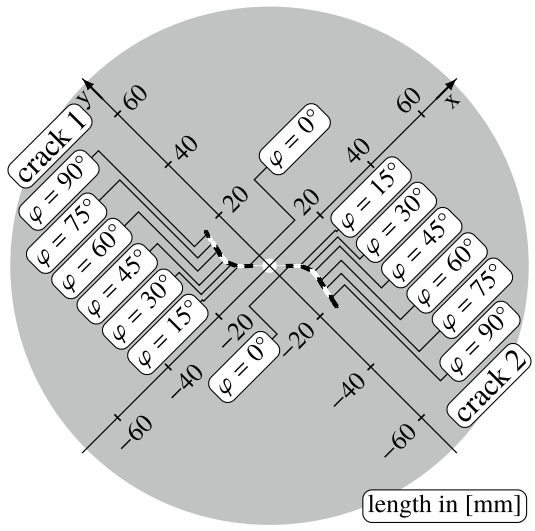

(b)

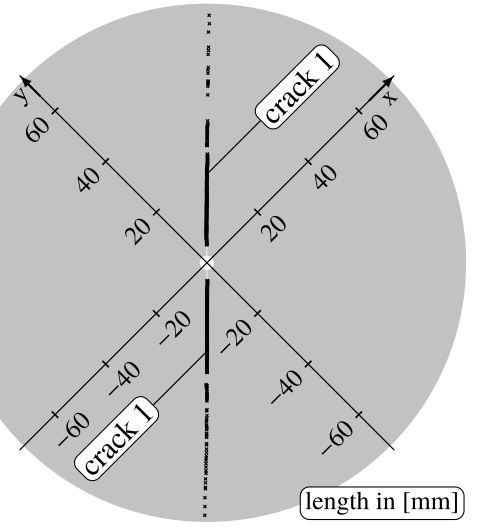

(d)

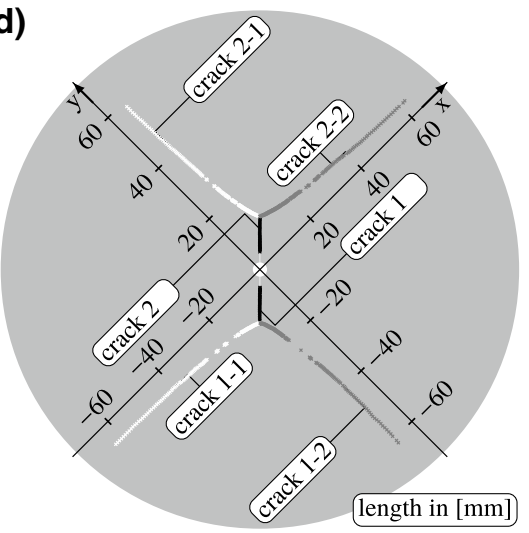

(f)

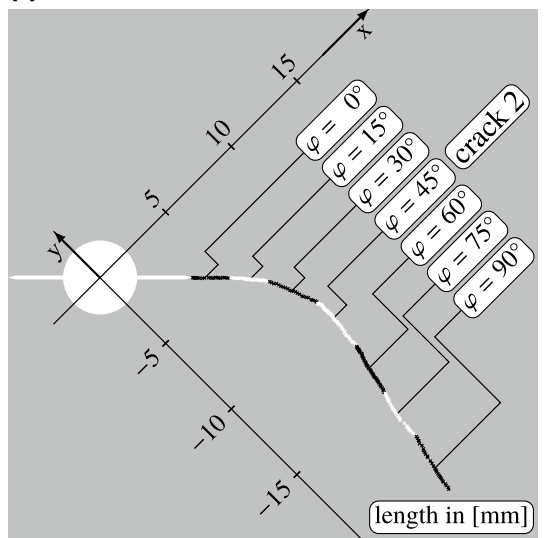

Fig. 14.11 Crack paths of the a uniaxially loaded specimen $\gg$ uni $\ll, \mathbf{b}$ equibiaxially loaded specimen $\gg$ equi $\ll, \mathbf{c}$ first equibiaxially and afterwards phase-shifted loaded specimen $\gg 0^{\circ} / 22.5^{\circ} \ll$ with $\varphi=22.5^{\circ}$ and $\mathbf{d} \gg 0^{\circ} / 180^{\circ} \ll$ with $\varphi=180^{\circ}$. e First equibiaxially and afterwards phase-shifted loaded specimen »stepw. $0^{\circ}-90^{\circ} \ll$ with a stepwise increase of the phase shift in steps of $15^{\circ}$ with $0^{\circ} \leq \varphi \leq 90^{\circ}$. f Enlarged view of (e), crack 2 [77] 
(a)

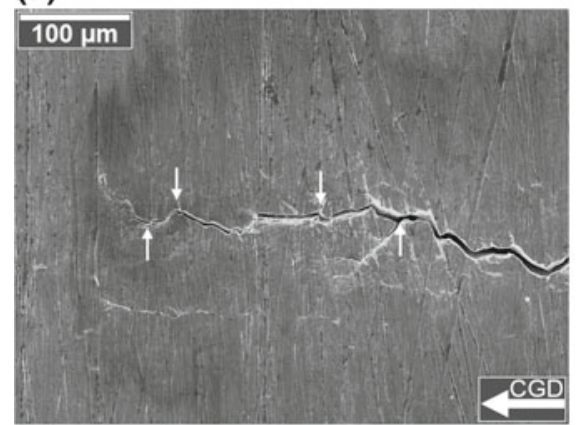

(c)

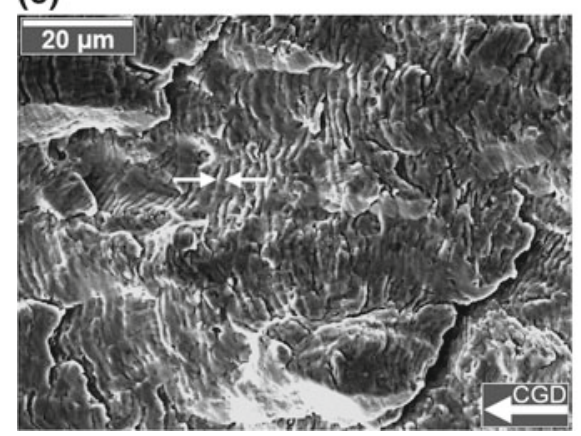

(b)

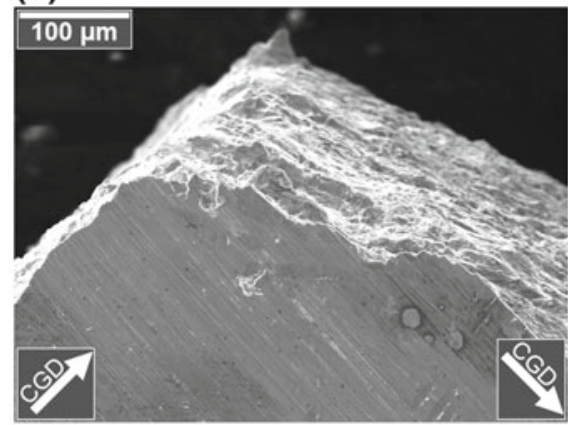

(d)

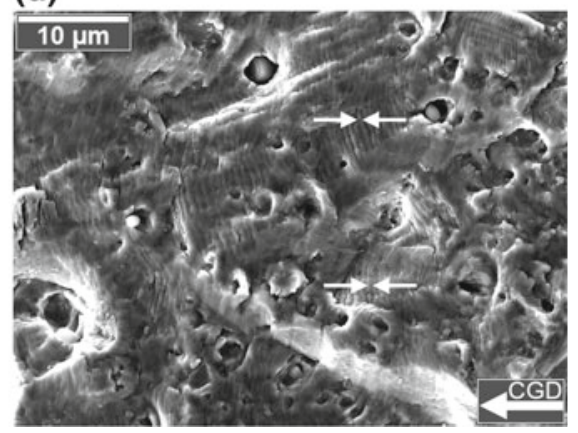

Fig. 14.12 SEM micrographs with crack growth direction (CGD) of the a crack paths and the $\mathbf{b}-\mathbf{d}$ fractured surfaces of the specimens $\mathbf{a}, \mathbf{c} \gg$ equi $\ll$ as well as $\mathbf{b}, \mathbf{d} \gg 0^{\circ} / 180^{\circ} \ll$. $\mathbf{a}$ Crack path of crack 1 of the specimen »equi $\ll$ at the end of the investigation. $\mathbf{b}$ Triple point of crack 1 branching into cracks $1-1$ and $1-2$ of the steel specimen $\gg 0^{\circ} / 180^{\circ} \ll$. c Fractured surface of crack 1 of specimen »equi« at a crack length of $a \approx 70 \mathrm{~mm}\left(\Delta K_{\text {eq }} \approx 70 \mathrm{MPa} \sqrt{\mathrm{m}}\right)$. d Fractured surface of crack 1-2 of specimen $\gg 0^{\circ} / 180^{\circ} \ll$ at a crack length of $a \approx 60 \mathrm{~mm}\left(\Delta K_{\text {eq }} \approx 80 \mathrm{MPa} \sqrt{\mathrm{m}}\right)$ [77]

due to a small Mode II component, cf. [76], due to the slight phase shift $\varphi$. In the two changes of the phase shift $\varphi$, i.e. from $\varphi=15^{\circ}$ to $\varphi=30^{\circ}$ and from $\varphi=30^{\circ}$ to $\varphi=45^{\circ}$, a significant kinking of the crack path occured. In addition to kinking at a large angle, microbranching was observed at both changes of phase shift, Fig. $14.13 \mathrm{~b}$, c. The further increases of the phase shift by $15^{\circ}$ had no further pronounced impact on the crack path.

\subsubsection{Crack Growth Rates}

The consideration of crack growth is carried out with both $a-N$ plots, Fig. $14.14 \mathrm{a}, \mathrm{b}$, and $\mathrm{d} a / \mathrm{d} N-\Delta K$ plots, Fig. $14.14 \mathrm{c}, \mathrm{d}$. In addition to the symmetrical crack paths, the courses of the $a-N$ curves of both cracks or even all four cracks were also identical. 
(a)

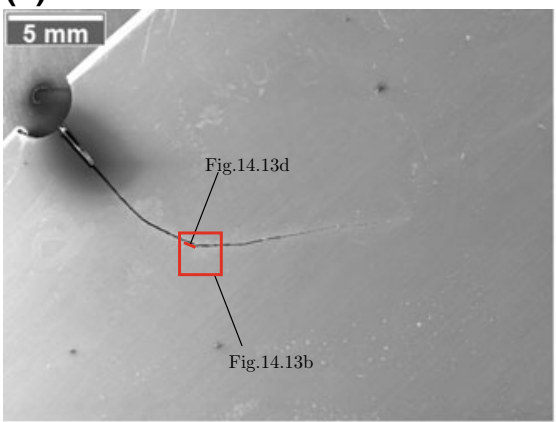

(c)

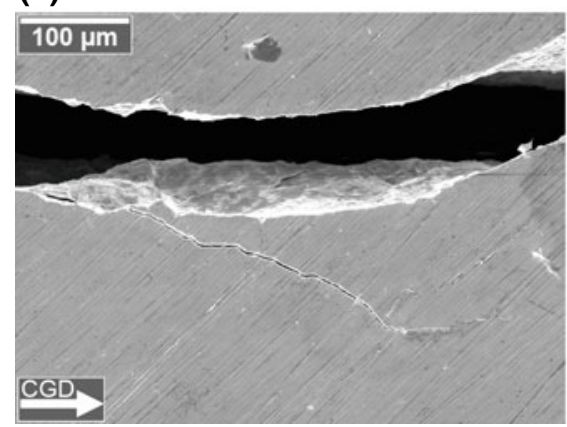

(b)

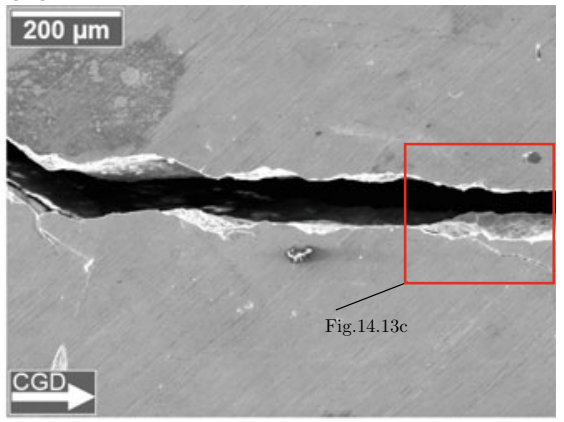

(d)

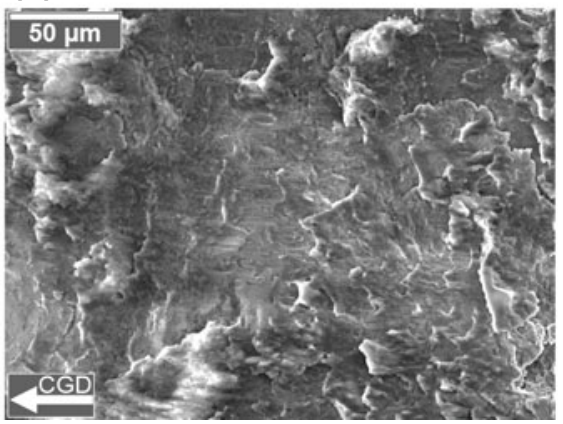

Fig. 14.13 SEM micrographs with crack growth direction (CGD) of the a-c crack paths and d the fractured surface of specimen $\gg$ stepw. $0^{\circ}-90^{\circ} \ll$. a Location of the enlarged view of image (b). b Location of the enlarged view of image (c). c Branching and subbranching as well as d face friction at the transition from straight to curved crack path, cf. Fig 14.13a [76]

Therefore only one complete crack with all of its branched cracks is plotted in the $a-N$ and $\mathrm{d} a / \mathrm{d} N-\Delta K$ plots.

The $a-N$ plot initially shows two main $a-N$ curves, cf. Fig. $14.14 \mathrm{a}$. The uniaxially loaded specimen »uni « appears to grow faster than the equibiaxially loaded specimen »equi «. However, the $\mathrm{d} a / \mathrm{d} N-\Delta K$ plot clearly shows that crack growth occured at almost the same rate $\mathrm{d} a / \mathrm{d} N$ at the same cyclic stress intensity $\Delta K_{\text {eq. }}$. The differences in the course of the $a-N$ curve can be found in the specimen thickness and the various load situations, i.e. the equivalent stress intensity ranges were different for the same crack lengths, cf. [76]. The crack growth rate of the specimen »equi« was checked by measuring the fatigue striations in the captured SEM image, cf. Fig. 14.12c. The mean value of 10 load cycles was an increase of the crack length of $\Delta a \approx 1.5 \mu \mathrm{m}$ per load cycle. This is consistent with the measurement and calculation of the crack growth rate $\mathrm{d} a / \mathrm{d} N$ using crack gage and the Fractomat, cf. Fig. 14.14c grey dots at $\Delta K_{\mathrm{eq}} \approx 70 \mathrm{MPa} \sqrt{\mathrm{m}}$ with $\mathrm{d} a / \mathrm{d} N=1.5 \times 10^{-3} \mathrm{~mm}$ per load cycle. By means of the $\mathrm{d} a / \mathrm{d} N-\Delta K$ course of the uniaxially and equibiaxially loaded specimens $\gg$ uni $\ll$ and »equi«, the Paris law was set up, cf. Fig. 14.14c, black dotted line. Thus a comparison 

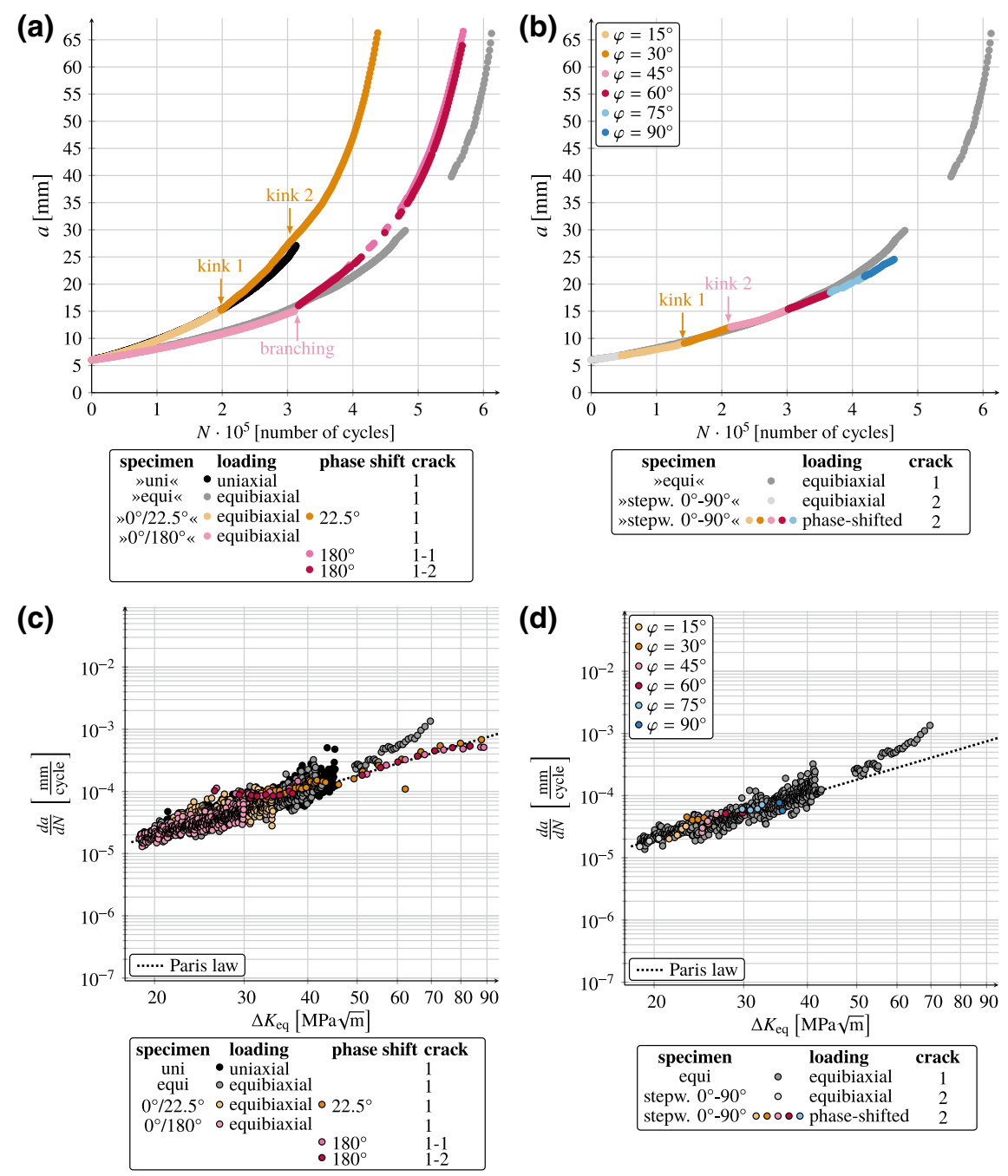

Fig. 14.14 Results of the fatigue crack growth experiments [76, 77]. $a-N$ plots of specimens a »uni «, »equi «, $\gg 0^{\circ} / 22.5^{\circ} \ll$ and $\gg 0^{\circ} / 180^{\circ} \ll$ and $\mathbf{b} \gg s t e p w .0^{\circ}-90^{\circ} \ll$ with representation of the phase shift $\varphi$ compared to the equibiaxially loaded specimen »equi $\ll . \mathrm{d} a / \mathrm{d} N-\Delta K$ plots of specimens $\mathbf{c} \gg$ uni $\ll, ~ \gg$ equi $\ll, ~ \gg 0^{\circ} / 22.5^{\circ} \ll$ and $\gg 0^{\circ} / 180^{\circ} \ll$ and $\mathbf{d} \gg$ stepw. $0^{\circ}-90^{\circ} \ll$ with representation of the phase shift $\varphi$ compared to the equibiaxially loaded specimen »equi $\ll$ $[76,77]$ 
of the crack growth rates $\mathrm{d} a / \mathrm{d} N$ under phase-shifted loading is possible with uniaxial or rather equibiaxial loading.

Specimen $\gg 0^{\circ} / 22.5^{\circ} \ll$ was first equibiaxially loaded and afterwards loaded with a phase shift of $\varphi=22.5^{\circ}$. The equibiaxially loaded crack of the specimen $\gg 0^{\circ} / 22.5^{\circ} \ll$ followed the course of the uniaxially loaded specimen »uni« in the $a-N$ plot, cf. Fig. 14.14a. The comparison of the crack growth rate $\mathrm{d} a / \mathrm{d} N$ versus the cyclic stress intensity factor $\Delta K$ reveals, that the crack growth rate was similar to the crack growth rate of the equibiaxially loaded specimen »equi«, cf. Fig. 14.14c. It has to be noted, that a thickness correction had to be carried out for calculation of $\Delta K$, cf. [76]. Natural scattering in crack growth, as reported in [109], which is e.g. caused by inhomogeneities [110] can be excluded in the PM material.

The course of the $a-N$ plot of the specimen $\gg 0^{\circ} / 22.5^{\circ} \ll$ shows two kinks, cf. Fig. 14.14a, orange dots. The first kink occured after changing from in-phase to out-of-phase loading. This change led to a change in the crack opening Mode. As long as the crack was loaded equibiaxially, it was pure Mode I crack opening. As soon as the crack was loaded with phase shift, a Mixed Mode crack opening occurred. The kink in the $a-N$ plot correlates with the start of the kinking of the crack path, cf. Fig. 14.11c. The second kink in the $a-N$ plot occurred at the end of the kinking of the crack path, i.e. when no further curvature occured. The first kink in the $a-N$ plot provided a faster fatigue crack growth rate and the second kink provided a slower fatigue crack growth rate. The reason for the faster crack growth was the Mode II portion of crack opening or rather the cyclic stress intensity factor $\Delta K_{\text {eq }}$. This is in accordance to the findings of [48], that Mode II loaded cracks grow faster than Mode I loaded cracks.

Specimen $\gg 0^{\circ} / 180^{\circ} \ll$ was first equibiaxially loaded and afterwards loaded with a phase shift of $\varphi=180^{\circ}$. As long as the crack was equibiaxially loaded, the course of the $a-N$ plot of the specimen $\gg 0^{\circ} / 180^{\circ} \ll$ is identical to the $a-N$ course of the equibiaxially loaded specimen »equi «, cf. Fig. 14.14a, because both specimens had an almost identical thickness and were subjected to the same loading. Thus, the crack growth rates were almost equal for equibiaxial loading, cf. Fig. 14.14c. The subsequent change from in-phase loading to out-of-phase loading of specimen $\gg 0^{\circ} / 180^{\circ} \ll$ with a phase shift of $\varphi=180^{\circ}$ led to a branching of the crack into two cracks. The two branched cracks seem to grew faster if one compares the $a-N$ curves of both cracks with the $a-N$ curves of the equibiaxially loaded specimen »equi«, cf. Fig. 14.14a. A comparison of the crack growth rates of the branched cracks with Paris' law line shows that first an accelerated fatigue crack growth took place in the two branched cracks, cf. Fig. 14.14c, red dots. After a certain crack growth, the crack growth rate followed Paris' law. The initially accelerated crack growth was due to the Mixed Mode loading. The decrease of the Mode II portion with increasing crack length at the two branched cracks led to the fact that the crack growth finally took place again under Mode I crack opening and the crack growth rate followed Paris' law. This is consistent with the findings by Wang et al. [48] who have found that Mode II loaded cracks grow faster than Mode I loaded cracks. The reduction of the Mode II fraction in the crack growth can be verified by FE calculations and SEM images. The crack growth rate measured with a scanner camera and then calculated could 
also be validated with SEM images. At a crack length of about $60 \mathrm{~mm}$, an average increase of the crack length of $\Delta a \approx 0.7 \mu \mathrm{m}$ per load cycle was measured as an average of 10 fatigue striations, cf. Fig. 14.12d. This is in accordance with the calculated crack growth rates, cf. Fig. $14.14 \mathrm{c}$ red dots at $\Delta K_{\text {eq }} \approx 80 \mathrm{MPa} \sqrt{\mathrm{m}}$ with $\mathrm{d} a / \mathrm{d} N=0.7 \cdot 10^{-3} \mathrm{~mm}$ per load cycle.

Specimen $\gg$ stepw. $0^{\circ}-90^{\circ} \ll$ was first equibiaxially loaded and afterwards phaseshifted loaded with a subsequent increase of the phase shift. As long as the crack was equibiaxially loaded, the course of the $a-N$ plot of the specimen $\gg$ stepw. $0^{\circ}-90^{\circ} \ll$ equals the $a-N$ course of the equibiaxially loaded specimen $\gg$ equi $\ll$, cf. Fig. 14.14b, because both specimens had an almost identical thickness and were subjected to the same loading. Furthermore, the crack growth rates were almost equal for equibiaxial loading, cf. Fig. 14.14d. In addition to the kinks in the crack path caused by the change in the phase shift $\varphi$, cf. Fig. 14.11e, f, kinks in the $a-N$ curve can also be observed, cf. Fig. 14.14b. Analogous to the crack path, a kink in the $a-N$ curve occured at the change from a phase-shifted loading of $\varphi=15^{\circ}$ to a phase-shifted loading of $\varphi=30^{\circ}$, cf. Fig. $14.14 \mathrm{~b}$. As with specimen $\gg 0^{\circ} / 22.5^{\circ} \ll$, the accelerated crack growth can be explained by Mode II contribution. The Mode II portion on the fatigue crack growth can also be seen on the fractured surface, where face friction is clearly visible, cf. Fig. 14.13d. In addition to the increased crack growth rate, the change of the phase shift $\varphi$ reduced the cyclic equivalent crack intensity factor $\Delta K_{\text {eq }}$, cf. Fig. 14.14d. The second kink occured when the phase shift was changed from $\varphi=30^{\circ}$ to $\varphi=45^{\circ}$. Initially, a slightly slower fatigue crack growth for the $\varphi=45^{\circ}$ loaded crack was observed, cf. Fig. 14.14d. Subsequently, the fatigue crack growth followed Paris' law.

\subsection{Conclusions}

The material behavior of a powder metallurgically produced high alloy X5CrMnNi167-6 austenitic stainless steel was investigated under both quasi-static and cyclic loading for low cycle fatigue and fatigue crack growth. The following results were achieved in quasi-static tests:

- The yield surface can be described by von Mises criterion.

- Sequence tests with permanently changing $\lambda$ showed load sequence effects, i.e. a kinematic hardening with $\alpha^{\prime}$-martensite formation was observed.

- The highest martensite volume fraction was measured for shear loading.

The following results were achieved in low cycle fatigue tests:

- The fatigue life of low cycle fatigue tests can be divided into three stages: (i) primary hardening, (ii) softening and (iii) secondary hardening as observed for uniaxial tests by [7, 31, 32]. 
- The lowest fatigue lives were determined for loads with strain ratio of $\Phi=$ $-0.5,-0.1$ and 0.5 , the highest fatigue lives were determined for shear loading $\Phi=-1$.

- During secondary hardening, the von Mises force amplitude $F_{\mathrm{vM}} / 2$ increased.

- The larger the von Mises strain amplitude increased, the more $\alpha^{\prime}$-martensite was formed.

- The highest amount of $\alpha^{\prime}$-martensite was induced and the highest numbers of cycles to failure occurred for shear loading.

- Deviations of equivalent force amplitudes and fatigue lives can also be interpreted that the von Mises hypothesis cannot be applied in the case of multiaxial elasticplastic cyclic loading.

The following results were achieved in fatigue crack growth investigations:

- The crack paths of the two single cracks of each specimen or in the further course the four branched cracks of specimen $\gg 0^{\circ} / 180^{\circ} \ll$ revealed a symmetrical course.

- Differences in the $a-N$ curves were due to differences in the specimens thickness and different load cases, respectively.

- The calculation of the cyclic stress intensity factor was based on the proposed geometry functions. This made a simple comparison with kinked or branched cracks under phase-shifted loading possible.

- It became clear that phase shift loaded cracks initially grew at an accelerated crack growth rate under Mode II crack opening. By kinking or branching, the Mode II proportion of the crack tip loading decreased in the further course and the crack growth rate followed the Paris' law.

Acknowledgements The authors thank and acknowledge gratefully funding of subproject B4 within Collaborative Research Center TRIP-Matrix-Composites (Project number 54473466-CRC 799) by the German Research Foundation or Deutsche Forschungsgemeinschaft (DFG). Further thanks go to Dipl.-Ing. Kai Nagel, Dr.-Ing. Dirk Kulawinski and Dipl.-Ing. Stephanie Ackermann, who were involved in the experiments. In particular, the authors want to thank the colleagues of the Collaborative Research Center for their support and cooperation.

\section{References}

1. S. Henkel, D. Kulawinski, S. Ackermann, H. Biermann, in Moderne Methoden der Werkstoffprüfung (Wiley-VCH, 2015), pp. 121-157. https://doi.org/10.1002/9783527670673.ch4

2. L. Krüger, S. Wolf, U. Martin, S. Martin, P.R. Scheller, A. Jahn, A. Weiß, J. Phys. Conf. Ser. 240, 012098 (2010). https://doi.org/10.1088/1742-6596/240/1/012098

3. A. Jahn, A. Kovalev, A. Weiß, S. Wolf, L. Krüger, P.R. Scheller, Steel Res. Int. 82(1), 39 (2010). https://doi.org/10.1002/srin.201000228

4. S. Martin, C. Ullrich, D. Šimek, U. Martin, D. Rafaja, J. Appl. Crystallogr. 44(4), 779 (2011). https://doi.org/10.1107/s0021889811019558

5. A. Weidner, A. Glage, H. Biermann, Procedia Eng. 2(1), 1961 (2010). https://doi.org/10. 1016/j.proeng.2010.03.211

6. A. Weidner, S. Martin, V. Klemm, U. Martin, H. Biermann, Scr. Mater. 64(6), 513 (2011). https://doi.org/10.1016/j.scriptamat.2010.11.028 
7. M. Bayerlein, H.J. Christ, H. Mughrabi, Mater. Sci. Eng. A 114, L11 (1989). https://doi.org/ 10.1016/0921-5093(89)90871-x

8. D. Hennessy, G. Steckel, C. Altstetter, Metall. Trans. A 7(3), 415 (1976). https://doi.org/10. 1007/bf02642838

9. A. Hannon, P. Tiernan, J. Mater. Process. Technol. 198(1-3), 1 (2008). https://doi.org/10. 1016/j.jmatprotec.2007.10.015

10. J.P. Boehler, S. Demmerle, S. Koss, Exp. Mech. 34(1), 1 (1994). https://doi.org/10.1007/ bf02328435

11. C.H. Busche, Bestimmung und Beschreibung des Elastizitätsmoduls von Blechwerkstoffen nach dem Umformen (Shaker Verlag, 2007)

12. S. Demmerle, J. Boehler, J. Mech. Phys. Solids 41(1), 143 (1993). https://doi.org/10.1016/ 0022-5096(93)90067-p

13. V. Bonnand, J. Chaboche, P. Gomez, P. Kanouté, D. Pacou, Int. J. Fatigue 33(8), 1006 (2011). https://doi.org/10.1016/j.ijfatigue.2010.12.018

14. M.W. Brown, K.J. Miller, Proc. Inst. Mech. Eng. 187(1), 745 (1973). https://doi.org/10.1243/ pime_proc_1973_187_161_02

15. M. Parsons, K. Pascoe, Mater. Sci. Eng. 22, 31 (1976). https://doi.org/10.1016/00255416(76)90133-6

16. T. Ogata, Y. Takahashi, in Multiaxial Fatigue and Fracture (Elsevier, 1999), pp. 101-114. https://doi.org/10.1016/s1566-1369(99)80010-7

17. S. Henkel, J. Fischer, L. Balogh, T. Ungar, H. Biermann, J. Phys. Conf. Ser. 240, 012042 (2010). https://doi.org/10.1088/1742-6596/240/1/012042

18. S. Ackermann, D. Kulawinski, S. Henkel, H. Biermann, Int. J. Fatigue 67, 123 (2014). https:// doi.org/10.1016/j.ijfatigue.2014.02.007

19. T. Itoh, M. Sakane, M. Ohnami, J. Eng. Mater. Technol. 116(1), 90 (1994). https://doi.org/ 10.1115/1.2904261

20. K.J. Pascoe, J.W.R. de Villiers, J. Strain Anal. 2(2), 117 (1967). https://doi.org/10.1243/ $03093247 \mathrm{v} 022117$

21. T. Yokobori, H. Yamanouchi, S. Yamamoto, Int. J. Fract. Mech. 1(1), 3 (1965). https://doi. org/10.1007/bf00184149

22. V. Doquet, Fatigue Fract. Eng. Mater. Struct. 20(2), 227 (1997). https://doi.org/10.1111/j. 1460-2695.1997.tb00280.x

23. D. Kulawinski, S. Ackermann, A. Glage, S. Henkel, H. Biermann, Steel Res. Int. 82(9), 1141 (2011). https://doi.org/10.1002/srin.201100111

24. B.R. You, S.B. Lee, Int. J. Fatigue 18(4), 235 (1996). https://doi.org/10.1016/01421123(96)00002-3

25. E. Macha, C.M. Sonsino, Fatigue Fract. Eng. Mater. Struct. 22(12), 1053 (1999). https://doi. org/10.1046/j.1460-2695.1999.00220.x

26. M.W. Brown, K.J. Miller, Fatigue Fract. Eng. Mater. Struct. 1(2), 231 (1979). https://doi.org/ 10.1111/j.1460-2695.1979.tb00380.x

27. R. Lohr, E.G. Ellison, Fatigue Fract. Eng. Mater. Struct. 3(1), 1 (1980). https://doi.org/10. 1111/j.1460-2695.1980.tb01101.x

28. T. Itoh, M. Sakane, M. Ohnami, D.F. Socie, J. Eng. Mater. Technol. 117(3), 285 (1995). https://doi.org/10.1115/1.2804541

29. A. Fatemi, D.F. Socie, Fatigue Fract. Eng. Mater. Struct. 11(3), 149 (1988). https://doi.org/ 10.1111/j.1460-2695.1988.tb01169.x

30. A. Glage, A. Weidner, H. Biermann, Proc. Eng. 2(1), 2085 (2010). https://doi.org/10.1016/j. proeng.2010.03.224

31. A. Glage, A. Weidner, H. Biermann, Steel Res. Int. 82(9), 1040 (2011). https://doi.org/10. 1002/srin.201100080

32. U. Krupp, C. West, H.J. Christ, Mater. Sci. Eng. A 481-482, 713 (2008). https://doi.org/10. 1016/j.msea.2006.12.211

33. M. Smaga, F. Walther, D. Eifler, Mater. Sci. Eng. A 483-484, 394 (2008). https://doi.org/10. 1016/j.msea.2006.09.140 
34. A. Burgold, S. Henkel, S. Roth, M. Kuna, H. Biermann, Mater. Test. 60(4), 341 (2018). https:// doi.org/10.3139/120.111156

35. D.F. Martelo, A.M. Mateo, M.D. Chapetti, Int. J. Fatigue 80, 406 (2015). https://doi.org/10. 1016/j.ijfatigue.2015.06.029

36. H.J. Lim, Y.J. Lee, H. Sohn, Mech. Syst. Sig. Process. 120, 356 (2019). https://doi.org/10. 1016/j.ymssp.2018.10.018

37. O. Scott-Emuakpor, T. George, C. Cross, M.H.H. Shen, AIAA J. 48(1), 63 (2010). https:// doi.org/10.2514/1.39296

38. P.R.G. Anderson, G.G. Garrett, Int. J. Fract. 16(3), R111 (1980). https://doi.org/10.1007/ bf00013388

39. C.D. Hopper, K.J. Miller, J. Strain Anal. Eng. Des. 12(1), 23 (1977). https://doi.org/10.1243/ $03093247 \mathrm{v} 121023$

40. S. Henkel, C.H. Wolf, A. Burgold, M. Kuna, H. Biermann, Fract. Struct. Int. 13, 135 (2019). https://doi.org/10.3221/igf-esis.48.16

41. E. Breitbarth, M. Besel, S. Reh, Int. J. Fatigue 108, 116 (2018). https://doi.org/10.1016/j. ijfatigue.2017.12.005

42. E. Breitbarth, M. Besel, Int. J. Fatigue 113, 345 (2018). https://doi.org/10.1016/j.ijfatigue. 2018.04.021

43. G. Dhondt, C. Kontermann, Proceedings of 6th International Conference Crack Paths (CP 2018). Conference USB flash drive (Verona (I), 2018)

44. V. Giannella, G. Dhondt, C. Kontermann, R. Citarella, Int. J. Fatigue 123, 296 (2019). https:// doi.org/10.1016/j.ijfatigue.2019.02.029

45. C.F. Qian, M.O. Wang, B.J. Wu, S.H. Dai, J.C.M. Li, J. Eng. Mater. Technol. 118(3), 349 (1996). https://doi.org/10.1115/1.2806817

46. C.F. Qian, M.O. Wang, B.J. Wu, S.H. Dai, J.C.M. Li, J. Eng. Mater. Technol. 118(3), 356 (1996). https://doi.org/10.1115/1.2806818

47. S. Mall, V. Perel, Int. J. Fatigue 74, 166 (2015). https://doi.org/10.1016/j.ijfatigue.2015.01. 005

48. M.O. Wang, R.H. Hu, C.F. Qian, J.C.M. Li, Fatigue Fract. Eng. Mater. Struct. 18(12), 1443 (1995). https://doi.org/10.1111/j.1460-2695.1995.tb00867.x

49. R.K. Neerukatti, S. Datta, A. Chattopadhyay, N. Iyyer, N. Phan, Fatigue Fract. Eng. Mater. Struct. 41(2), 387 (2017). https://doi.org/10.1111/ffe.12690

50. E.U. Lee, R.E. Taylor, Eng. Fract. Mech. 78(8), 1555 (2011). https://doi.org/10.1016/j. engfracmech.2010.11.005

51. R. Yuuki, K. Akita, N. Kishi, Fatigue Fract. Eng. Mater. Struct. 12(2), 93 (1989). https://doi. org/10.1111/j.1460-2695.1989.tb00516.x

52. H. Kitagawa, R. Yuuki, K. Tohgo, Fatigue Fract. Eng. Mater. Struct. 2(2), 195 (1979). https:// doi.org/10.1111/j.1460-2695.1979.tb01355.x

53. Z. Zhu, Z. Lu, P. Zhang, W. Fu, C. Zhou, X. He, Met. 9(8), 823 (2019). https://doi.org/10. 3390/met9080823

54. V. Shlyannikov, A. Zakharov, Eng. Fract. Mech. 123, 86 (2014). https://doi.org/10.1016/j. engfracmech.2014.02.013

55. H.E. Misak, V.Y. Perel, V. Sabelkin, S. Mall, Int. J. Fatigue 55, 158 (2013). https://doi.org/ 10.1016/j.ijfatigue.2013.06.003

56. V. Shlyannikov, A. Tumanov, A. Zakharov, Theor. Appl. Fract. Mech. 73, 68 (2014). https:// doi.org/10.1016/j.tafmec.2014.06.016

57. M. Lepore, F. Berto, D. Kujawski, Theor. Appl. Fract. Mech. 100, 14 (2019). https://doi.org/ 10.1016/j.tafmec.2018.12.008

58. A. Shanyavskiy, Eng. Fract. Mech. 78(8), 1516 (2011). https://doi.org/10.1016/j. engfracmech.2011.01.019

59. V. Shlyannikov, A. Zakharov, Theor. Appl. Fract. Mech. 91, 52 (2017). https://doi.org/10. 1016/j.tafmec.2017.03.014

60. C. Dalle Donne, K.H. Trautmann, H. Amstutz, in Multiaxial Fatigue and Deformation: Testing and Prediction (ASTM International, 2000), pp. 405-422. https://doi.org/10.1520/stp13517s 
61. R. Sunder, B. Ilchenko, Int. J. Fatigue 33(8), 1101 (2011). https://doi.org/10.1016/j.ijfatigue. 2010.11.018

62. C.D. Donne, Übertragbarkeit von Risswiderstandskurven von Standardproben auf biaxial belastete, bauteilähnliche Kreuzproben (VDI Verlag, 1997)

63. A. Makinde, L. Thibodeau, K.W. Neale, Exp. Mech. 32(2), 138 (1992). https://doi.org/10. 1007/bf02324725

64. I.H. Wilson, D.J. White, J. Strain Anal. 6(1), 27 (1971). https://doi.org/10.1243/ 03093247v061027

65. S. Taira, K. Tanaka, M. Kan, A. Yamada, Proc. 22nd Japan Cong. Mat. Res. pp. 130-137 (1979)

66. T. Hoshide, K. Tanaka, A. Yamada, Fatigue Fract. Eng. Mater. Struct. 4(4), 355 (1981). https:// doi.org/10.1111/j.1460-2695.1981.tb01132.x

67. K. Tanaka, T. Hoshide, A. Yamada, S. Taira, Fatigue Fract. Eng. Mater. Struct. 2(2), 181 (1979). https://doi.org/10.1111/j.1460-2695.1979.tb01354.x

68. P. Bold, M. Brown, R. Allen, Wear 144(1-2), 307 (1991). https://doi.org/10.1016/00431648(91)90022-m

69. M.W. Brown, K.J. Miller, in Multiaxial Fatigue (ASTM International, 1985), pp. 135-153. https://doi.org/10.1520/stp36221s

70. S. Datta, A. Chattopadhyay, N. Iyyer, N. Phan, Int. J. Fatigue 109, 103 (2018). https://doi. org/10.1016/j.ijfatigue.2017.12.018

71. S. Henkel, D. Holländer, M. Wünsche, H. Theilig, P. Hübner, H. Biermann, S. Mehringer, Eng. Fract. Mech. 77(11), 2077 (2010). https://doi.org/10.1016/j.engfracmech.2010.04.013

72. V.N. Shlyannikov, Eng. Fract. Mech. 108, 3 (2013). https://doi.org/10.1016/j.engfracmech. 2013.03.011

73. H. Theilig, D. Hartmann, M. Wünsche, S. Henkel, P. Hübner, Key Eng. Mater. 348-349, 857 (2007). https://doi.org/10.4028/www.scientific.net/kem.348-349.857

74. A.C. Pickard, J. Strain Anal. Eng. Des. 50(1), 25 (2014). https://doi.org/10.1177/ 0309324714551082

75. S. Henkel, E. Liebelt, H. Biermann, S. Ackermann, Fract. Struct. Int. 9(34), 466 (2015). https://doi.org/10.3221/IGF-ESIS.34.52

76. C.H. Wolf, S. Henkel, A. Burgold, Y. Qiu, M. Kuna, H. Biermann, Adv. Eng. Mater. 21(5), 1800861 (2018). https://doi.org/10.1002/adem.201800861

77. C.H. Wolf, S. Henkel, A. Burgold, Y. Qiu, M. Kuna, H. Biermann, Int. J. Fatigue 124, 595 (2019). https://doi.org/10.1016/j.ijfatigue.2019.03.011

78. S. Xiao, M. Brown, in Mechanical Behaviour of Materials V (Elsevier, 1988), pp. 659-664. https://doi.org/10.1016/b978-0-08-034912-1.50089-8

79. M.. Wang, R.H. Hu, C.J. Zhang, S.H. Dai, in Proceedings of the 7th International Conference on Pressure Vessel Technology, vol. 2 (VdTÜV, 1992), pp. 1413-1427

80. J.J. Kibler, R. Roberts, J. Eng. Ind. 92(4), 727 (1970). https://doi.org/10.1115/1.3427838

81. E. önch, D. Galster, Br. J. Appl. Phys. 14(11), 810 (1963). https://doi.org/10.1088/0508-3443/ $14 / 11 / 319$

82. J. Granlund, Structural steel plasticity: experimental study and theoretical modelling. Ph.D. thesis, Lulea University of Technology, 1997

83. J. Gozzi, Plastic behaviour of steel: Experimental investigation and modelling. Ph.D. thesis, Lulea University of Technology, 2004

84. J. Gozzi, A. Olsson, O. Lagerqvist, Exp. Mech. 45(6), 533 (2005). https://doi.org/10.1007/ bf02427907

85. D. Kulawinski, S. Ackermann, A. Seupel, T. Lippmann, S. Henkel, M. Kuna, A. Weidner, H. Biermann, Mater. Sci. Eng. A 642, 317 (2015). https://doi.org/10.1016/j.msea.2015.06. 083

86. M. Kuroda, V. Tvergaard, Acta Mater. 47(14), 3879 (1999). https://doi.org/10.1016/s13596454(99)00213-x

87. D. Kulawinski, K. Nagel, S. Henkel, P. Hübner, H. Fischer, M. Kuna, H. Biermann, Eng. Fract. Mech. 78(8), 1684 (2011). https://doi.org/10.1016/j.engfracmech.2011.02.021 
88. A. Samir, A. Simon, A. Scholz, C. Berger, Int. J. Fatigue 28(5-6), 643 (2006). https://doi.org/ 10.1016/j.ijfatigue.2005.08.010

89. C.M. Sonsino, V. Grubisic, Materialwiss. Werkstofftech. 15(11), 378 (1984). https://doi.org/ 10.1002/mawe.19840151104

90. A.A. Griffith, Proceedings of the 1st International Congress for Applied Mechanics (Delft, 1924), pp. 55-63

91. C.H. Wolf, A. Burgold, S. Henkel, M. Kuna, H. Biermann, Proceedings of 12th International Conference on Multiaxial Fatigue and Fracture (2019) (In press)

92. A. Savitzky, M.J.E. Golay, Anal. Chem. 36(8), 1627 (1964). https://doi.org/10.1021/ ac60214a047

93. ASTM E647-15e1, Standard test method for measurement of fatigue crack growth rates. Technical Report (ASTM International, West Conshohocken, PA, 2015)

94. S. Ackermann, T. Lippmann, D. Kulawinski, S. Henkel, H. Biermann, Fract. Struct. Int. (34), 580 (2015). https://doi.org/10.3221/IGF-ESIS.34.64

95. J. Talonen, P. Aspegren, H. Hänninen, Mater. Sci. Technol. 20(12), 1506 (2004). https://doi. org/10.1179/026708304x4367

96. D. Mohr, M. Oswald, Exp. Mech. 48(1), 65 (2007). https://doi.org/10.1007/s11340-0079053-9

97. D. Mohr, J. Jacquemi, J. Mech. Phys. Solids 56(10), 2935 (2008). https://doi.org/10.1016/j. jmps.2008.07.003

98. A. Olsson, Stainless steel plasticity: material modelling and structural applications. Ph.D. thesis, Lulea University of Technology, 2001

99. S. Martin, S. Wolf, U. Martin, L. Krüger, Solid State Phenom. 172-174, 172 (2011). https:// doi.org/10.4028/www.scientific.net/ssp.172-174.172

100. A. Weidner, C. Segel, H. Biermann, Mater. Lett. 143, 155 (2015). https://doi.org/10.1016/j. matlet.2014.12.098

101. G.B. Olson, M. Cohen, Metall. Trans. A 6(4), 791 (1975). https://doi.org/10.1007/bf02672301

102. A. Nitta, T. Ogata, K. Kuwabara, Fatigue Fract. Eng. Mater. Struct. 12(2), 77 (1989). https:// doi.org/10.1111/j.1460-2695.1989.tb00515.x

103. D. Infante-Garcia, G. Qian, H. Miguélez, E. Giner, Int. J. Fatigue 123, 87 (2019). https://doi. org/10.1016/j.ijfatigue.2019.01.019

104. M. Kuna, Finite Elements in Fracture Mechanics (Springer, Netherlands, 2013). https://doi. org/10.1007/978-94-007-6680-8

105. F. Erdogan, G.C. Sih, J. Basic Eng. 85(4), 519 (1963). https://doi.org/10.1115/1.3656897

106. L. Pook, Eng. Fract. Mech. 167, 2 (2016). https://doi.org/10.1016/j.engfracmech.2016.02. 055

107. H. Richard, A. Eberlein, G. Kullmer, Eng. Fract. Mech. 174, 10 (2017). https://doi.org/10. 1016/j.engfracmech.2016.12.005

108. R. Brighenti, A. Carpinteri, A. Spagnoli, Acta Mech. 225(11), 3123 (2014). https://doi.org/ 10.1007/s00707-014-1111-7

109. C. Lapetra, J. Mayo, J. Dominguez, Fatigue Fract. Eng. Mater. Struct. 19(5), 589 (1996)

110. D.A. Virkler, B.M. Hillberry, P.K. Goel, J. Eng. Mater. Technol. 101(2), 148 (1979). https:// doi.org/10.1115/1.3443666 
Open Access This chapter is licensed under the terms of the Creative Commons Attribution 4.0 International License (http://creativecommons.org/licenses/by/4.0/), which permits use, sharing, adaptation, distribution and reproduction in any medium or format, as long as you give appropriate credit to the original author(s) and the source, provide a link to the Creative Commons license and indicate if changes were made.

The images or other third party material in this chapter are included in the chapter's Creative Commons license, unless indicated otherwise in a credit line to the material. If material is not included in the chapter's Creative Commons license and your intended use is not permitted by statutory regulation or exceeds the permitted use, you will need to obtain permission directly from the copyright holder. 